NASA Technical Memorandum 105977

AIAA-93-0398

\title{
Icing Effects on Aircraft Stability and Control Determined From Flight Data
}

\author{
Preliminary Results
}

T.P. Ratvasky and R.J. Ranaudo

Lewis Research Center

Cleveland, Ohio

Prepared for the

31st Aerospace Sciences Meeting and Exhibit

sponsored by the American Institute of Aeronautics and Astronautics

Reno, Nevada, January 11-14, 1993 


\title{
ICING EFFECTS ON AIRCRAFT STABILITY AND CONTROL DETERMINED FROM FLIGHT DATA. Preliminary Results.
}

\author{
T.P. Ratvasky, and R.J. Ranaudo \\ National Aeronautics and Space Administration \\ Lewis Research Center \\ Cleveland, Ohio 44135
}

\begin{abstract}
:
The effects of airframe icing on the stability and control characteristics of the NASA DH-6 Twin Otter icing research aircraft were investigated by flight test. The flight program was developed to obtain the stability and control parameters of the DH-6 in a baseline ("uniced") configuration and an "artificially iced" configuration for specified thrust conditions. Stability and control parameter identification maneuvers were performed over a wide range of angles of attack for wing flaps retracted $\left(0^{\circ}\right)$ and wing flaps partially deflected $\left(10^{\circ}\right)$. Engine power was adjusted to hold thrust constant at one of three thrust coefficients $\left(C_{T}=0.14, C_{T}=0.07, C_{T}=0.00\right)$.

This paper presents only the pitching- and yawing-moment results from the flight test program. Stability and control parameters were estimated for the uniced and artificially iced configurations using a modified stepwise regression algorithm. Comparisons of the uniced and iced stability and control parameters are presented for the majority of the flight envelope. The artificial ice reduced the elevator and rudder control effectiveness by $12 \%$ and $8 \%$ respectively for the $0^{\circ}$ flap setting. The longitudinal static stability was also decreased substantially (approximately 10\%) because of the tail ice. Further discussion is provided to explain some of the effects of ice on the stability and control parameters.
\end{abstract}

List of Symbols and Abbreviations:

\begin{tabular}{|c|c|c|c|}
\hline$A_{X}, A_{Y}, A_{Z}$ & $\begin{array}{l}\text { longitudinal, lateral, and vertical } \\
\text { accelerations, respectively, g units }\end{array}$ & $\mathrm{p}, \mathrm{q}, \mathrm{r}$ & $\begin{array}{l}\text { roll rate, pitch rate, and yaw rate, } \\
\text { respectively, rad } / \mathrm{s} \text { or } \mathrm{deg} / \mathrm{s}\end{array}$ \\
\hline $\mathrm{b}$ & wing span, $\mathrm{m}$ & $\mathrm{R}^{2}$ & squared multiple correlation coefficient \\
\hline \multirow[t]{2}{*}{$\mathrm{C}_{\mathrm{m}}, \mathrm{C}_{\mathrm{n}}$} & pitching-, yawing-moment coefficients, & $\mathrm{S}$ & wing area, $\mathrm{m}^{2}$ \\
\hline & respectively & V & total airspeed, $\mathrm{m} / \mathrm{s}$ or knots \\
\hline $\mathrm{C}_{\mathrm{m} 0}, \mathrm{C}_{\mathrm{n} 0}$ & $\begin{array}{l}\text { initial conditions of pitching-, yawing- } \\
\text { moment coefficients, respectively }\end{array}$ & $x_{y}(t)$ & $\begin{array}{l}\text { measured aircraft response or control } \\
\text { surface input }\end{array}$ \\
\hline $\mathrm{C}_{\mathrm{T}}$ & thrust coefficient & $y(t)$ & computed aerodynamic coefficients \\
\hline $\bar{c}$ & mean aerodynamic chord, m & $\alpha$ & angle of attack, rad or deg \\
\hline $\mathrm{cg}$ & aircraft center of gravity & $\beta$ & angle of sideslip, rad or deg \\
\hline g & acceleration due to gravity, $\mathrm{m} / \mathrm{s}^{2}$ & $\triangle$ & change in parameter due to ice shape \\
\hline $\mathrm{I}_{\mathrm{X}}, \mathrm{I}_{\mathrm{Y}}, \mathrm{I}_{\mathrm{Z}}$ & $\begin{array}{l}\text { moments of inertia about roll, pitch, } \\
\text { and yaw axes, respectively, } \mathrm{kg}-\mathrm{m}^{2}\end{array}$ & $\delta_{c}, \delta_{a}, \delta_{r}$ & $\begin{array}{l}\text { elevator, aileron, and rudder } \\
\text { deflection, respectively, rad or deg }\end{array}$ \\
\hline L & product of inertia, $\mathrm{kg}-\mathrm{m}^{2}$ & $\delta_{\mathrm{F}}$ & flap deflection, rad or deg \\
\hline
\end{tabular}


$\Theta \quad$ aerodynamic stability and control parameters

$\Theta_{0} \quad$ constant offset term

$\Theta_{j} \quad$ derivative with respect to jth response or control surface input

$\theta, \phi \quad$ pitch and roll angles, respectively, rad or deg

$\sigma \quad$ standard deviation estimate of measurement noise
AMI Analytical Methods, Inc.
LeRC NASA Lewis Research Center
MSR modified stepwise regression
PID parameter identification
WFF NASA Wallops Flight Facility

Pitching moment derivatives:

$$
C_{m_{a}}=\frac{\partial C_{m}}{\partial \alpha}, \quad C_{m_{q}}=\frac{\partial C_{m}}{\partial \frac{q \bar{c}}{2 V}}, \quad C_{m_{b_{e}}}=\frac{\partial C_{m}}{\partial \delta_{e}}
$$

Yawing moment derivatives:

$$
C_{n_{\beta}}=\frac{\partial C_{n}}{\partial \beta}, \quad C_{n_{p}}=\frac{\partial C_{n}}{\partial \frac{p b}{2 V}}, \quad C_{n_{r}}=\frac{\partial C_{n}}{\partial \frac{r b}{2 V}}, \quad C_{n_{\phi_{r}}}=\frac{\partial C_{n}}{\partial \delta_{r}}
$$




\section{Introduction:}

A principal objective of the NASA Lewis Research Center's (LeRC) icing research program is to develop and validate computational methods for predicting the effects of airframe icing on aircraft flight characteristics. Recently a multi-year contract was awarded to Analytical Methods, Inc. (AMI) to develop a three -dimensional flow code to predict the stability effects and performance losses of a complete aircraft with known ice contamination. The code will be validated with wind tunnel data supplied by a large commercial aircraft company and full-scale flight data from NASA LeRC's icing research aircraft.

NASA's DeHavilland DH-6 Twin Otter icing research aircraft was utilized in an extensive flight test program to acquire the needed flight data base. Although the DH-6 does not represent the geometry of a modern swept wing transport, it does provide numerous advantages in terms of it's low operating cost, simplicity, adaptability for the intended experiment, and known flight characteristics from previous stability and control flight experiments ${ }^{1}$. Also, a digitized panel model of the DH-6 that was previously developed ${ }^{2}$, was available for performing the AMI code validation.

Relying on extensive past experience in measuring icing effects on aircraft performance, stability and control ${ }^{3}$, NASA developed a comprehensive flight program to generate the required aerodynamic data base. The key elements of the flight program include:

1. A high-fidelity, onboard instrumentation system with complete system characteristics known from comprehensive ground and flight calibration tests.

2. Use of measured aircraft weights, center of gravity, and moments of inertia for data reduction and analysis programs.

3. Flight testing at specific thrust settings $\left(\mathrm{C}_{\mathrm{T}}=\right.$ $\left.0.14, C_{T}=0.07, C_{T}=0.00\right)$ to distinguish power effects from icing effects on the derivative estimates. Previous experience indicated that power had a measurable effect on certain stability and control parameters ${ }^{4}$.

This report is organized in sections which describe the research aircraft, instrumentation systems, flight test procedures, data analysis methods, a discussion of the derivative estimates, and conclusions drawn from the work. Because of the volume of data acquired in the flight program, and the need for brevity in this particular report format, only the pitching- and yawing-moment results are presented. A complete data report will be written at a later time.

\section{Research Aircraft:}

The NASA Lewis icing research aircraft is a modified DeHavilland DH-6 Twin Otter (figure 1). It is powered by two 550 SHP Pratt and Whitney PT6A-20A turbine engines driving three-bladed Hartzell constant speed propellers. The flight controls are mechanically operated through a system of cables and pulleys. Control surfaces consist of elevator, ailerons, rudder, and wing flaps. Physical characteristics of the aircraft are in Table I.

The DH-6 was tested in a baseline configuration (clean airfoils), and an artificially iced configuration (figure 2). Artificial glaze ice shapes were attached to the leading edges of the horizontal and vertical stabilizers only. No other surfaces were contaminated. The ice shapes were determined by combining the geometry from actual tail ice photographs with a well-known ice area calculation procedure ${ }^{5}$. The ice shapes were cut from styrofoam blocks, and attached to the leading edges of the tail with double sided tape. The ice shapes did not incorporate surface roughness or 3D effects (scalloping).

Extensive ground tests were conducted on the DH-6 to obtain the center of gravity (cg) and moments of inertia along the longitudinal, lateral 
and vertical axes. These characteristics varied with fuel and crew loading and any modifications that were made. Aircraft configuration was closely monitored to account for any changes in center of gravity and moments of inertia.

For that phase of testing when the DH-6 engines were shut down while in flight, an auxiliary power unit (APU) was installed to supply the research equipment with electrical power. The aircraft was modified structurally and electrically to accommodate the APU.

\section{Instrumentation System:}

The stability and control data system flown on the Twin Otter incorporated the following components: inertial data, air data, control surface deflection data, signal conditioning, data acquisition and recording systems. The inertial sensors consisted of three orthogonally mounted linear accelerometers, three orthogonally mounted angular rate gyros, and a vertical gyro to provide pitch and roll angle data. These sensors were near the aircraft center of gravity. Yaw angle data was provided by the ship's directional gyro. Air data consisted of airspeed, angle of attack, angle of sideslip, pressure altitude, and outside air temperature. All air data parameters (except OAT) were sensed by a Rosemount 858 probe head extended from the aircraft on a 9 foot noseboom. The control surface deflections, $\left(\delta_{\mathrm{c}}, \delta_{\mathrm{a}}, \delta_{\mathrm{r}}\right)$, were measured using linear control position transducers (CPT's) located near the control horns which eliminated cable stretching errors. Transducer signals were amplified and filtered by a Precision Filters System 6000 unit and then digitized with a Keithley series 500 data acquisition system. A total of 26 channels of data were digitized at an acquisition rate of 100 samples/second and a 12 bit resolution. A ruggedized AT-class microcomputer was used to control the data acquisition system, and a removable hard drive in the computer provided data storage. See table II for instrumentation specifications.
Extensive calibrations were conducted on all components of the data system. Individual calibrations were conducted for all sensors, and through-put calibrations (sensor-filter-data acquisition-recording) were run where possible. Calibrations were checked periodically during the research program.

\section{Flight Test Procedures:}

Aircraft weight and balance were determined before each flight by weighing the fully fueled aircraft less crew. In flight, fuel totalizers provided an accurate measure of fuel burned. These readings were used for $\mathrm{cg}$ and moment of inertia calculations in the post flight data processing.

Flight testing in the two configurations (baseline, artificially iced) was performed with wing flaps retracted $\left(\delta_{\mathrm{F}}=0^{\circ}\right)$, and with wing flaps partially extended $\left(\delta_{\mathrm{F}}=10^{\circ}\right)$. Test point airspeeds were selected to cover the range of angles of attack in each configuration from maximum cruise airspeed to near aerodynamic stall. Parameter identification (PID) maneuvers consisting of elevator doublets (figure 3) and rudder-aileron doublets (figure 4) were used to excite the required aircraft response.

To determine the power effects, each PID maneuver was flown at three target thrust coefficients $\left(\mathrm{C}_{\mathrm{T}}\right): \mathrm{C}_{\mathrm{T}}=0.14$ (high thrust), $\mathrm{C}_{\mathrm{T}}=0.07$ (low thrust), and $\mathrm{C}_{\mathrm{T}}=0.00$ (engines off and propellers feathered). To attain the target thrust coefficients in the powered cases, a simple flight procedure was developed. Initially, an altitude would be selected where flight conditions were smooth. This became the reference pressure altitude for all flight maneuvers. The outside air temperature was also recorded. Based on the pre-planned indicated test airspeeds, and a constant 1800 propeller rpm, the required engine torque pressure settings were calculated from known relationships between thrust coefficient, engine power coefficient, propeller advance ratio, and propeller efficiency. Normally, the target thrust 
coefficients did not provide level flight conditions at the trimmed test airspeeds. Consequently, the PID maneuvers were usually performed in shallow climbs or descents as the aircraft reached the reference pressure altitude. Generally, all PID maneuvers were accomplished within \pm 200 feet of the reference altitude.

The tests at $\mathrm{C}_{\mathrm{T}}=0.00$ were performed at the NASA Wallops Flight Facility (WFF), where a restricted test area, tracking support, and a dedicated landing site were employed for flight safety reasons. In performing these tests, the DH-6 departed WFF and climbed to a pre-planned altitude and position which was within safe gliding distance to the landing field. While being tracked on radar, the engines were shut down and the propellers feathered. Test airspeeds were attained by establishing the proper flight path. PID maneuvers were then executed while the onboard data system, powered by the auxiliary power unit, recorded the flight data. The glide was terminated and the engines re-started when a specified minimum altitude was reached.

\section{Data Analysis:}

Measured data were recorded with the onboard data acquisition system in a binary format. Data were post-test processed into engineering units and corrected for instrument offsets from the aircraft center of gravity, position errors in airspeed and altitude, and upwash effects in the angle of attack measurements.

Each flight contained a series of data compatibility maneuvers designed to verify sensor and data system integrity. These maneuvers were analyzed using a maximum likelihood algorithm ${ }^{6}$ to estimate bias and scale factor errors in the data system. The analysis indicated a small sidewash correction was required in the sideslip measurement. This correction was made prior to the stability and control parameter estimation.
The stability and control derivatives were estimated using a Modified Stepwise Regression (MSR) technique ${ }^{7}$. MSR is a version of linear regression which can determine the structure of the aerodynamic model, and estimate the values of the model parameters. The general form of the aerodynamic model is as follows:

$$
y(t)=\Theta_{0}+\Theta_{1} x_{1}(t)+\Theta_{2} x_{2}(t)+\ldots+\Theta_{n} x_{n}(t)
$$

$y(t)$ represents the aerodynamic force or moment coefficient and is known from measurement.

$\Theta_{0}$ is a constant corresponding to the initial flight condition.

$\Theta_{1}$ to $\Theta_{n}$ are constant coefficients known as stability and control derivatives.

$\mathrm{x}_{1}(\mathrm{t})$ to $\mathrm{x}_{\mathrm{h}}(\mathrm{t})$ terms represent the measured input and output variables, or their combinations (regressors).

MSR determines the model structure one term at a time. Each new term enters into the regression equation based on the largest correlation with the dependent variable, $y(t)$, after adjusting for the effect of the previously selected terms on $y(t)$. Essentially, the first regressor $\mathrm{x}(\mathrm{t})$ is selected based on the highest correlation with the dependent variable $y(t)$. A constant value, $\theta_{j}$, is determined to minimize the squared difference in the measured aerodynamic coefficient $y(t)$, and the model prediction $\Theta_{0}+\Theta_{j} x_{(}(t)$. It means that at each step of the MSR, the parameters are obtained by minimizing the following least squares cost function:

$$
J_{M S R}=\sum_{i=1}^{N}\left[y(i)-\Theta_{0}-\sum_{j=1}^{l} \Theta_{j} x_{j}(i)\right]^{2}
$$

$\mathrm{N}$ is the number of data points

$l+1$ is the number of parameters in the regression equation. 
In addition, at each regression step the influence of individual derivative/regressor pairs on the model is re-evaluated. The estimated parameters, $\Theta_{j}$, may be retained, or removed from the model due to their statistical significance. The process of adding and deleting terms to the model continues until no further significant terms can be admitted to the model, and no further insignificant terms can be removed.

Models based solely on significance of individual parameters has proven to contain too many terms for good predictability ${ }^{8}$. Criteria for selecting adequate models are the squared multiple correlation coefficient $\left(\mathrm{R}^{2}\right)$, and the $\mathrm{F}$-statistic value. The $\mathrm{R}^{2}$ value indicates the percent of variation cxplained by the model. An $\mathrm{R}^{2}$ close to $100 \%$ suggests the model perfectly fits the measured data. The F-statistic value is the ratio of regression mean square to residual mean square. The model with the maximum $\mathrm{F}$-value has been recommended as the 'best' one for a given set of data. ${ }^{9}$ Both criteria were used in this analysis.

\section{Results:}

The analysis performed for this report was limited to the pitching and yawing moment coefficients. Ice on the horizontal and vertical stabilizers strongly affects these moment coefficients because the moments are predominantly created by the lift generated from these tail surfaces. Ice contamination may reduce the maximum lift and lift-curve slopes of the stabilizers, which could result in lower stability of the aircraft. Separated flows behind the ice shape may decrease the effectiveness of control surfaces, which results in reduced controllability of the aircraft.

The effect of ice on the pitching and yawing moment coefficients is evaluated by comparing the values of stability and control derivatives for both the baseline (uniced) and iced cases. Each stability and control derivative and its standard error was estimated using the MSR technique described above. Each flight condition was repeated to provide an ensemble of data. From the ensemble, a better measure of the variance of the derivatives was made.

The stability and control derivatives are plotted with respect to trim angle of attack in figures 5-14. For each parameter estimate, error bars representing $2 \sigma$ variance determined by MSR are included. To clarify trends between the baseline and iced configurations, a third order polynomial regression with respect to angle of attack was performed for each ensemble of data. Along with the regression line, a 95\% confidence bound on the mean was included to evaluate the statistical significance of configuration change due to icing.

\section{Longitudinal Model:}

The pitching moment coefficient was adequately modeled with the following equation:

$$
C_{m}=C_{m_{0}}+C_{m_{a}} \alpha+C_{m_{q}} \frac{q \bar{c}}{2 V}+C_{m_{b e}} \delta e
$$

The suitability of the model was determined chiefly by the $\mathrm{R}^{2}$ value and the $\mathrm{F}$ statistic value from the MSR program. For all data analyzed here, the $\mathrm{R}^{2} \geq 90 \%$, which indicates that over $90 \%$ of the variation of $\mathrm{C}_{\mathrm{m}}$ was described by this model.

The bias term $\mathrm{C}_{\mathrm{m} 0} \approx 0$ for all data runs because the elevator doublet inputs were initiated from trimmed conditions.

The derivative, $\mathrm{C}_{\mathrm{m} \alpha}$, is known as the static longitudinal stability derivative. A statically stable aircraft will have a negative $\mathrm{C}_{\mathrm{m} \alpha}$ indicating that a nose down moment is produced with a positive change in angle of attack. A more negative $C_{m \alpha}$ implies greater static longitudinal stability.

Figure 5 presents the effect of the tail ice on the static stability derivative with flaps retracted $\left(\delta_{\mathrm{F}}=0^{\circ}\right)$ for three thrust coefficients. Static stability was reduced by approximately $10 \%$ for each $C_{\mathrm{T}}$. 
Because of the exceptional repeatability in these data sets, the reduction in static stability due to tail ice was determined with high accuracy.

The effect of ice on $\mathrm{C}_{\mathrm{m} \alpha}$ with the flaps deflected to 10 degrees $\left(\delta_{\mathrm{F}}=10^{\circ}\right)$ is shown in figure 6. Similar to the $\delta_{\mathrm{F}}=0^{\circ}$ case, a reduction in static stability occurred because of the ice. However, the effect of ice varied with the thrust setting. Static stability was reduced by approximately $8 \%$ in the thrust cases, and $17 \%$ in the zero thrust case. Because of scatter in the derivative estimates, the reduction in $\mathrm{C}_{\mathrm{ms}}$ for the low thrust case $\left(\mathrm{C}_{\mathrm{T}}=0.07\right)$ was not statistically significant (i.e. the confidence bounds overlapped for most the range tested). Note that the least statically stable condition appeared at low angles of attack with flaps extended and a high thrust coefficient.

The derivative, $\mathrm{C}_{\mathrm{mq}}$, is known as the pitch damping derivative. As the aircraft pitches, a moment is created usually countering the pitching motion. The horizontal tailplane is the primary contributor to the pitch damping.

Figure 7 shows the effects of the ice on $\mathrm{C}_{\mathrm{mq}}$ with flaps retracted for three thrust coefficients. In the cases with thrust, the trends indicated a slightly lower pitch damping occurred due to the ice $(\Delta=5 \%)$. This reduction was statistically significant except at the low angles of attack where the confidence bounds intersected. For the zero thrust case, the pitch damping was virtually unaffected by the ice except at low angles of attack. The confidence bounds overlap for nearly the entire range of angles of attack tested. This result seemed inconsistent with the $\mathrm{C}_{\mathrm{m} \alpha}$ results because a loss in static longitudinal stability should also result in a reduction of pitch damping. Further discussion on this point will follow.

Figure 8 presents the effect of ice on $\mathrm{C}_{\mathrm{mq}}$ with the flaps deflected to 10 degrees $\left(\delta_{\mathrm{F}}=10^{\circ}\right)$. As with the $\delta_{\mathrm{F}}=0^{\circ}$ cases, pitch damping was reduced by $5 \%$ to $9 \%$ in the high and low thrust cases. Overlap in the confidence bounds occurred in the high thrust case at low angles of attack, but no overlap occurred in the low thrust case. For the zero thrust case, pitch damping was unaffected by the tail ice. The confidence bounds overlap for the entire angle of attack range tested, indicating that no change in $\mathrm{C}_{\mathrm{mq}}$ can be attributed to tail ice.

The derivative, $\mathrm{C}_{\mathrm{mbc}}$, is the elevator effectiveness control derivative. It is usually a negative value so that a positive elevator deflection results in a nose-down (i.e. negative) pitching moment. The more negative value for $C_{\text {inde }}$ indicates a more effective elevator.

In figure 9 , the effects of tail ice on $\mathrm{C}_{\text {mbe }}$ are shown for flaps retracted and three thrust coefficients. Because of the linearity in this data set, a first order regression was performed to indicate the trends. A clear separation exists between the baseline and iced cases for each thrust coefficient. The tail ice caused an approximate $12 \%$ loss in elevator effectiveness over the entire angle of attack range tested. Also, note that the slope of $\mathrm{C}_{\text {mbe }}$ with angle of attack changes with thrust condition. Engine power is clearly a factor in the elevator effectiveness with or without ice on the tail.

Figure 10 shows the effect of ice on $\mathrm{C}_{\mathrm{mbe}}$ with the flaps deflected to 10 degrees $\left(\delta_{\mathrm{F}}=10^{\circ}\right)$. As with the $\delta_{\mathrm{F}}=0^{\circ}$ cases, the ice decreased elevator effectiveness for all thrust settings $(\Delta \approx 16 \%)$. Also, the flaps appear to further decrease the dependence of elevator effectiveness with angle of attack.

\section{Lateral Model:}

The yawing moment coefficient was adequately modeled with the following equation:

$$
C_{n}=C_{n_{0}}+C_{n_{\beta}} \beta+C_{n_{p}} \frac{p b}{2 V}+C_{n_{r}} \frac{r b}{2 V}+C_{n_{\mathrm{br}}} \delta r
$$

The suitability of the model was determined chiefly by the $R^{2}$ value and the $F$ statistic value from the MSR program. For all data analyzed here, the 
$\mathrm{R}^{2} \geq 90 \%$, which indicates that over $90 \%$ of the variation of $C_{n}$ was described by this model.

The bias term $\mathrm{C}_{\mathrm{b} 0} \approx 0$ for all data runs because the rudder and aileron doublet inputs were initiated from trimmed conditions.

The derivative, $\mathrm{C}_{\mathrm{n} \beta}$, is the directional stability derivative ("weathercock" stability). A directionally stable aircraft will have positive $C_{h \beta}$ indicating a positive yawing moment is produced with a positive change in sideslip angle. The yawing moment will rotate the aircraft so as to decrease the sideslip. A more positive $\mathrm{C}_{\mathrm{n} \beta}$ implies a greater directional stability.

Figure 11 presents the effect of the vertical tail ice on $C_{n \beta}$ with flaps retracted $\left(\delta_{F}=0^{\circ}\right)$. For high and low thrust cases, the trends indicate that ice slightly decreased directional stability. However, the decrease is insignificant since the confidence limits overlap for most of the tested angle of attack range. For the zero thrust case, the ice decreased the directional stability $(\Delta \approx 20 \%)$ for all but the lowest and highest angles of attack. Also note that directional stability is greater with zero thrust than with power on.

The derivative, $\mathrm{C}_{\mathrm{np}}$, is the directional cross-derivative. It indicates the rate of change in the yawing moment due to roll rate. For most aircraft, $\mathrm{C}_{\mathrm{np}}$ is usually negative and of low value.

Figure 12 shows the effect of ice on $\mathrm{C}_{\mathrm{hp}}$ with flaps retracted $\left(\delta_{\mathrm{F}}=0^{\circ}\right)$ for three thrust conditions. For the zero thrust case, $\mathrm{C}_{\mathrm{np}}$ was not a significant term in the MSR model except at higher angles of attack. Regardless of the thrust condition, the effects of ice are negligible on $\mathrm{C}_{\mathrm{np}}$.

The derivative, $\mathrm{C}_{\mathrm{nr}}$, is the yaw damping derivative. It indicates the rate of change in the yawing moment due to yaw rate. The vertical tailplane is the primary contributor to the yaw damping. A larger vertical tail will likely increase yaw damping characteristics.
In figure 13, the effect of ice on $\mathrm{C}_{\mathrm{hr}}$ are shown for flaps retracted $\left(\delta_{\mathrm{F}}=0^{\circ}\right)$ and three thrust conditions. Although the data are fairly repeatable, the effects of ice on this derivative are negligible in each thrust case.

The derivative, $\mathrm{C}_{\mathrm{hor}}$, is the rudder effectiveness control derivative. It is usually a negative value so that a positive rudder deflection results in a negative yawing moment. A more negative value for $\mathrm{C}_{\mathrm{h} \delta \mathrm{r}}$ means a more effective rudder control.

Figure 14 presents the effect of ice on $\mathrm{C}_{\mathrm{h} \mathrm{br}_{\mathrm{r}}}$ with flaps retracted at three thrust conditions. Tail ice substantially reduced rudder effectiveness $(\Delta \approx 8 \%)$ in all thrust cases except for the higher angles of attack in the zero thrust case. This may be a result of low dynamic pressure at the rudder in the zero thrust condition.

\section{Discussion:}

From the results presented, it is clear that the ice on the tail surfaces considerably affect some of the aircraft stability and control parameters. Aircraft longitudinal static stability was reduced. Ice contamination reduced the horizontal tail's maximum-lift and lift-curve slope which resulted in a decreased pitching moment capability. Elevator and rudder control effectiveness decreased. Flow disturbances caused by the ice may have resulted in lower dynamic pressure at the control surfaces which decreased the effectiveness.

Other parameters indicated no change due to ice. The directional cross derivative, $\mathrm{C}_{\mathrm{np}}$, and directional damping derivative, $\mathrm{C}_{\mathrm{hr}}$, showed virtually no difference in the iced configuration. This indicates that these derivative were not sensitive to icing on this aircraft.

Two parameters, $\mathrm{C}_{\mathrm{mq}}$ and $\mathrm{C}_{\mathrm{h} \beta}$, had mixed results. Ice caused the pitch damping, $\mathrm{C}_{\mathrm{mq}}$, to slightly decrease with engine power on, but was unaffected by ice in the $C_{T}=0$ cases. Ice on the 
horizontal tail decreased the tail lift coefficient which should have caused a change in both the pitch damping and longitudinal stability, $\mathrm{C}_{\mathrm{m} \alpha}$. The tail ice clearly affected the $\mathrm{C}_{\mathrm{m} \alpha}$ in each thrust case, so similar changes were expected in $\mathrm{C}_{\mathrm{mq}}$. On further examination, $\mathrm{C}_{\mathrm{m} \alpha}$ was found to be much more sensitive to changes in the tail lift coefficient than $\mathrm{C}_{\mathrm{mq}}$. As a result, $\mathrm{C}_{\mathrm{mq}}$ may appear unaffected by the ice when $\mathrm{C}_{\mathrm{m} \alpha}$ was affected by the ice as was demonstrated in the $\mathrm{C}_{\mathrm{T}}=0$ cases. The second parameter which showed mixed results was the directional stability derivative, $\mathrm{C}_{\mathrm{h} \beta}$. It showed negligible changes due to tail ice with engine power on, but as much as $20 \%$ change in the zero thrust case. Also, $\mathrm{C}_{\mathrm{h} \beta}$ was greater in the zero thrust case for both baseline and iced configurations. One possible explanation is that the propeller wash had a more destablizing effect than the ice. Consequently, the effect of ice with engine power on appeared insignificant. Another possibility may be a shortcoming in the analysis technique. The effects of the vertical tail ice may not be apparent on $\mathrm{C}_{\mathrm{n} \beta}$ until $\beta>6^{\circ}$, but in these tests each $\mathrm{C}_{\mathrm{n} \beta}$ was evaluated about a $\beta \approx 0^{\circ}$. Analysis techniques are available to separate the data that was collected into small bins of $\beta$ so that $\mathrm{C}_{\mathrm{n} \beta}$ can be evaluated specifically at higher sideslip angles. These techniques will be applied for a future report.

Another interesting observation was the effect of aircraft configuration and flight condition on static longitudinal stability, $\mathrm{C}_{\mathrm{m} \alpha}$. Ice was shown to destablize the aircraft by $10 \%$ in the $\delta_{\mathrm{F}}=0^{\circ}$ cases and as much as $17 \%$ in the $\delta_{\mathrm{F}}=10^{\circ}$ cases. But the addition of flaps alone destablized the aircraft in the high thrust cases at lower angles of attack (see figures 5 and 6). For the uniced $\mathrm{C}_{\mathrm{T}}=0.14$ cases, at an $\alpha=0^{\circ}, \mathrm{C}_{\mathrm{m} \alpha}=-1.5$ for $\delta_{\mathrm{F}}=0^{\circ}$, and $\mathrm{C}_{\mathrm{m} \alpha}=-0.9$ for $\delta_{\mathrm{F}}=10^{\circ}$. This example illustrates a $40 \%$ reduction in static longitudinal stability with flaps deflected only $10^{\circ}$. Tail ice in conjunction with the $10^{\circ}$ flap deflection decreased static longitudinal stability by $50 \%$ for the same condition. It may be inferred that if flap deflection was increased beyond $10^{\circ}$ and the aircraft flown at $\alpha=0^{\circ}$, the static longitudinal stability would be lowered even more. The effect of tail ice with flaps deflected could drive the aircraft to a neutrally stable condition $\left(\mathrm{C}_{\mathrm{m} \alpha}=0\right)$. It is important to note that a high thrust condition with large flap deflections at low angles of attack may cause serious stability problems.

Finally, it also should be noted that the DH-6 is a short takeoff and landing (STOL) airplane. The tail surfaces are designed for low speed operations and tend to be oversized for the configurations and flight conditions that were tested. The changes in stability and control derivatives due to tail ice were sometimes small, but measurable. These changes were expected to be small because the DH-6 STOL capabilities make it more robust to ice. Other airplanes may show greater losses in stability and control for the conditions tested. 


\section{Conclusions:}

Based on the analysis and results presented, the following conclusions are made:

1. The test techniques and analysis methods employed permitted an accurate evaluation of the effects of moderate glaze tail ice on aircraft stability and control characteristics.

2. It was shown that ice on the horizontal and vertical tail surfaces significantly affect some aircraft stability and control parameters. The following parameters were affected:

- elevator and rudder control effectiveness was reduced by approximately $10 \%$ because of ice on the horizontal and vertical stabilizers

- static longitudinal stability was reduced by approximately $10 \%$ because of ice on horizontal stabilizer.

- directional stability was reduced by approximately $20 \%$ because of ice on the vertical tail for the zero thrust case.
3. It was shown that ice on the tail surfaces did not significantly affect some stability and control parameters. The following parameters were unaffected:

- yaw damping was not affected by the ice shapes on the tail surfaces.

- Pitch damping was reduced because of tail ice for the $C_{T}=(0.14,0.07)$ cases, but not at the $\mathrm{C}_{\mathrm{T}}=0$ case. Further investigation needs to be made to understand this result.

- directional stability was shown to be unaffected by ice for the powered cases, but further investigation needs to be made before this is conclusive. 


\section{References:}

1. Ranaudo, R.J., Batterson, J.G., et.al., Determination of Longitudinal Aerodynamic Derivatives Using Flight Data From an Icing Research Aircraft. AIAA Paper 89-0754, NASA TM 101427, 1989.

2. Norment, H.G., Three-Dimensional Trajectory Analyses of Two Drop Sizing Instruments: PMS OAP and PMS FSSP. NASA CR 4113, 1988.

3. Jordan, J.L., Platz, S.J., Schinstock, W.C., Flight Test Report of the NASA Icing Research Airplane. KSR 86-01, Kohlman Systems Research, Inc., Lawrence, KS, NASA CR-179515, 1986.

4. Ranaudo, R.J., et.al., The Measurement of Aircraft Performance and Stability and Control After Flight Through Natural Icing Conditions. AIAA Paper 86-9758, NASA TM-87265, 1986.

5. Bowden, D.T., Gensemer, A.E., Skeen, C.A., Engineering Summary of Airframe Icing Technical Data. General Dynamics /Convair, San Diego, CA, Technical Report ADS-4, 1964.

6. Klein, V., Morgan, D.R., Estimation of Bias Errors in Measured Airplane Responses Using Maximum Likelihood Method. NASA TM-89059, 1987.

7. Batterson, J.G., STEP and STEPSPL - Computer Programs for Aerodynamic Model Structure Determination and Parameter Estimation. NASA TM-86410, 1986.

8. Klein, V., Batterson, J.G., Murphy, P.C., Determination of Airplane Model Structure From Flight Data by Using Modified Stepwise Regression. NASA TP-1916, 1981.

9. Klein, V., Estimation of Aircraft Aerodynamic Parameters From Flight Data. Prog. Aerospace Sci. Vol 26, pp.1-77, 1989. 
Table I: Physical Characteristics of Research Aircraft

\begin{tabular}{|c|c|c|}
\hline CHARACTERISTIC & LOW & HIGH \\
\hline Mass, kg & 4510 & 4970 \\
\hline \multicolumn{3}{|l|}{ INERTIA: } \\
\hline $\mathrm{L}_{\mathrm{x}}, \mathrm{kg}-\mathrm{m}^{2}$ & 26190 & 26660 \\
\hline $\mathrm{L}_{\mathrm{Y}}, \mathrm{kg}-\mathrm{m}^{2}$ & 33460 & 34650 \\
\hline $\mathrm{I}_{\mathrm{Z}}, \mathrm{kg}-\mathrm{m}^{2}$ & 47920 & 51650 \\
\hline $\mathrm{L}_{\mathrm{xz}}, \mathrm{kg}-\mathrm{m}^{2}$ & 1490 & 1560 \\
\hline \multicolumn{3}{|l|}{ WING: } \\
\hline Area, $\mathrm{m}^{2}$ & \multicolumn{2}{|c|}{39.02} \\
\hline Aspect ratio & \multicolumn{2}{|c|}{10.06} \\
\hline Span, m & \multicolumn{2}{|c|}{19.81} \\
\hline Mean geometric chord, m & \multicolumn{2}{|c|}{1.98} \\
\hline Airfoil section (17\% thickness) & \multicolumn{2}{|c|}{ "DeHavilland High Lift" } \\
\hline \multicolumn{3}{|l|}{ HORIZONTAL TAIL: } \\
\hline Area, $\mathrm{m}^{2}$ & \multicolumn{2}{|c|}{9.10} \\
\hline Aspect ratio & \multicolumn{2}{|c|}{4.35} \\
\hline Span, m & \multicolumn{2}{|c|}{6.30} \\
\hline Mean geometric chord, $\mathrm{m}$ & \multicolumn{2}{|c|}{1.45} \\
\hline Airfoil section (inverted) & \multicolumn{2}{|c|}{ NACA $63 A 213$} \\
\hline
\end{tabular}

Table II: Instrument Specifications

\begin{tabular}{|c|c|c|}
\hline PARAMETER/SENSOR & RANGE & RESOLUTION \\
\hline $\mathrm{A}_{\mathrm{x}} \& \mathrm{~A}$, Sundstrand QA-700 & $\pm 1 \mathrm{~g}$ & $.0002 \mathrm{~g}$ \\
\hline $\mathrm{A}_{z}$, Sundstrand QA-700 & $+3 g,-1 g$ & $.0009 \mathrm{~g}$ \\
\hline p, Humphrey RG02-2324-1 & $\pm 60^{\circ} / \mathrm{s}$ & $0.0167^{\circ} / \mathrm{s}$ \\
\hline q, Humphrey RG02-2324-1 & $\pm 60^{\circ} / \mathrm{s}$ & $0.0167^{\circ} / \mathrm{s}$ \\
\hline r, Humphrey RG02-2324-1 & $\pm 120^{\circ} / \mathrm{s}$ & $0.0138^{\circ} / \mathrm{s}$ \\
\hline$\theta$, Humphrey VG24-0636-1 & $\pm 60^{\circ}$ & $0.0293^{\circ}$ \\
\hline$\phi$, Humphrey VG24-0636-1 & $\pm 90^{\circ}$ & $0.0439^{\circ}$ \\
\hline$\alpha$, Rosemount 858 & $+15^{\circ},-10^{\circ}$ & $0.003^{\circ}$ \\
\hline B, Rosemount 858 & $\pm 15^{\circ}$ & $0.003^{\circ}$ \\
\hline $\mathrm{V}$, Rosemount $542 \mathrm{~K}$ & 0 to $190 \mathrm{knot}$ & $0.076 \mathrm{knot}$ \\
\hline Alt., Rosemount $542 \mathrm{~K}$ & 0 to $15 \mathrm{~K} \mathrm{ft}$ & $8.2 \mathrm{ft}$ \\
\hline OAT, Rosemount 102AU1P & $-20^{\circ}$ to $30^{\circ} \mathrm{F}$ & $0.041^{\circ} \mathrm{F}$ \\
\hline$\delta_{\mathrm{a}, \mathrm{L}} \& \delta_{\mathrm{a} \cdot \mathrm{R}}, \mathrm{SAC}$ series 160 & $+19^{\circ},-16^{\circ}$ & $0.0091^{\circ}$ \\
\hline$\delta_{e}$, SAC series 160 & $+14^{\circ},-26^{\circ}$ & $0.0128^{\circ}$ \\
\hline$\delta_{r}$, SAC series 160 & $\pm 16^{\circ}$ & $0.0080^{\circ}$ \\
\hline
\end{tabular}



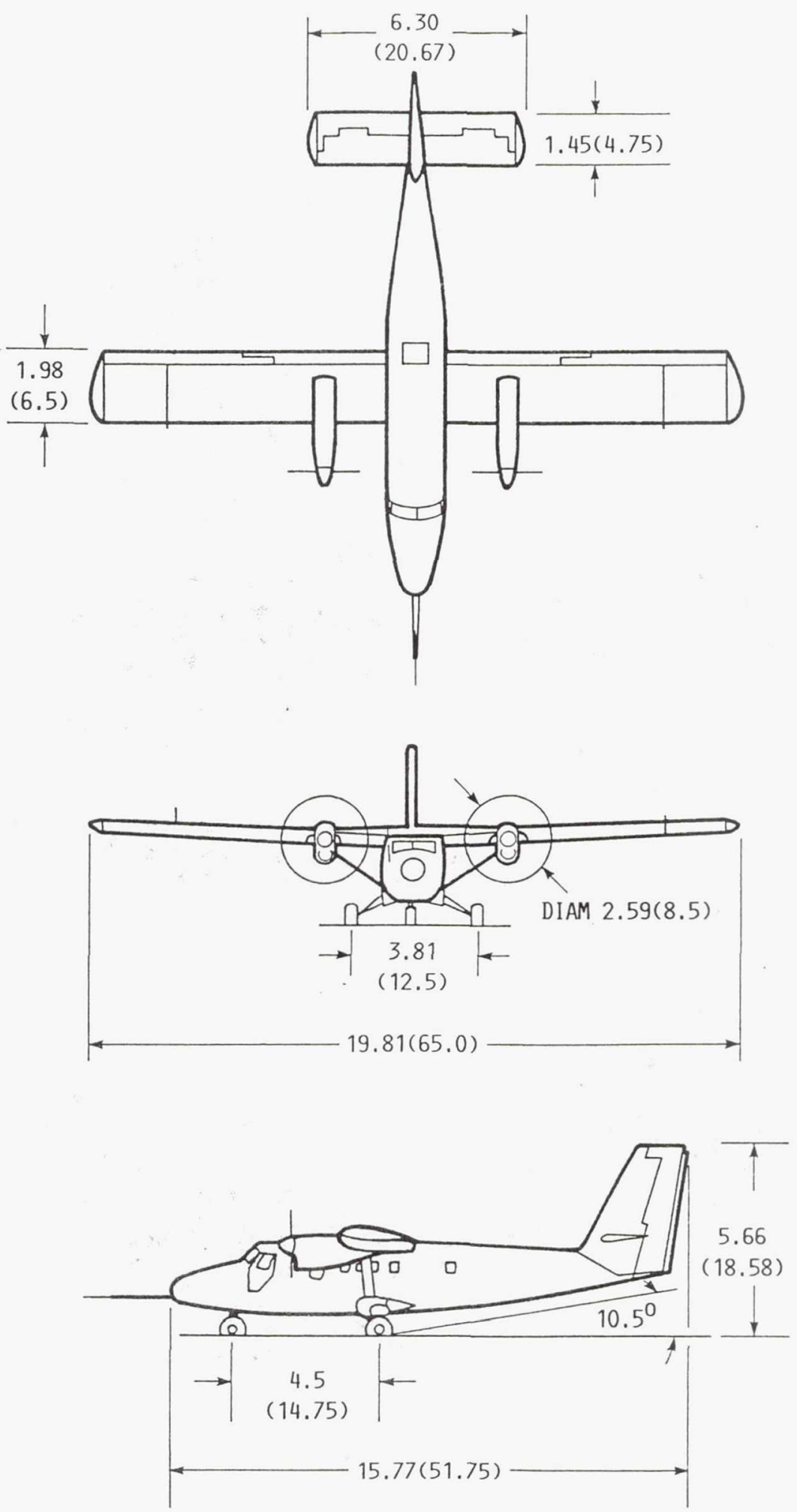

Figure 1: NASA Lewis Research Center Icing Research Aircraft: all dimensions are in meters (ft). 

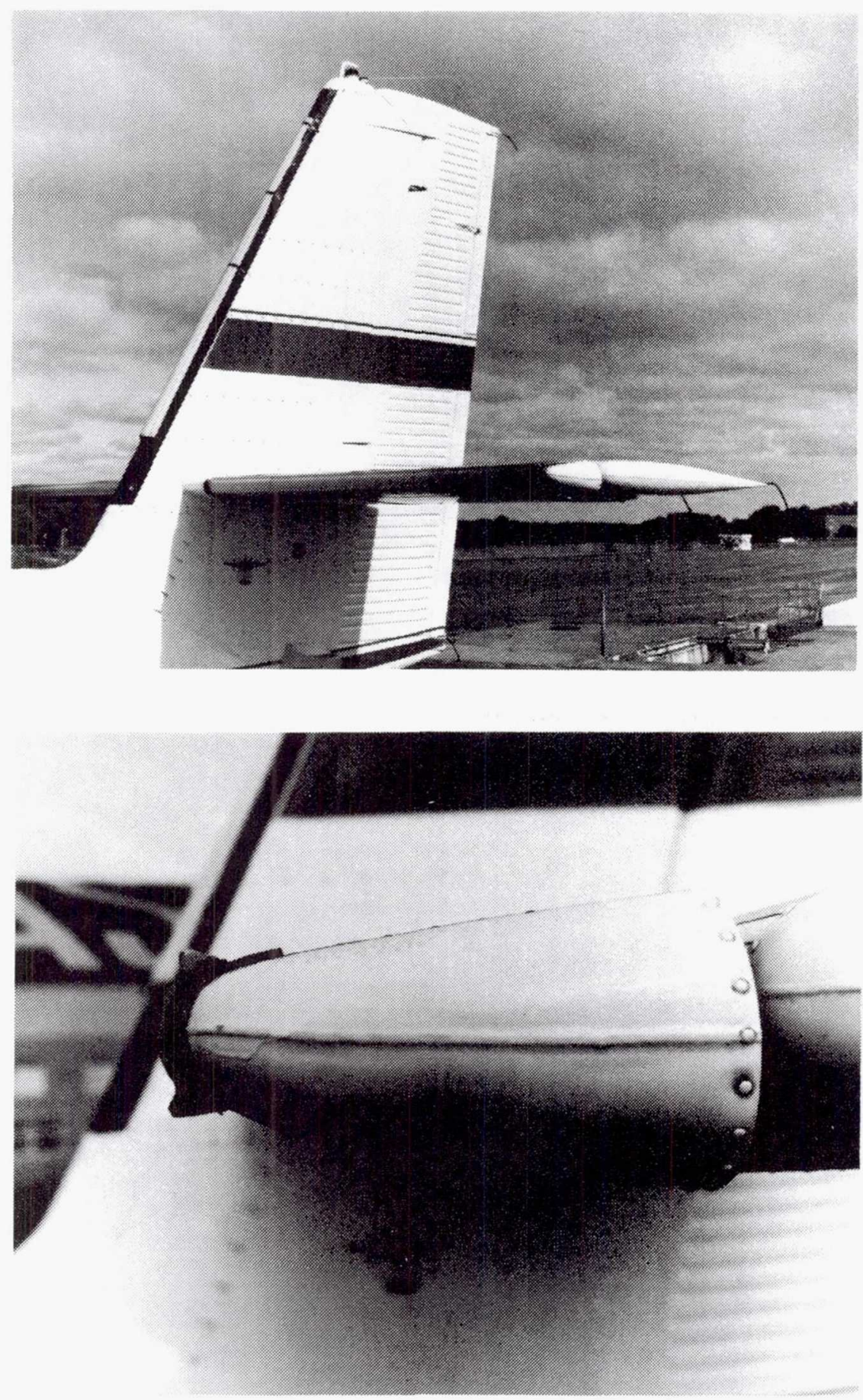

Figure 2: Artificial moderate glaze ice attached to horizontal and vertical stabilizers of the icing research aircraft 

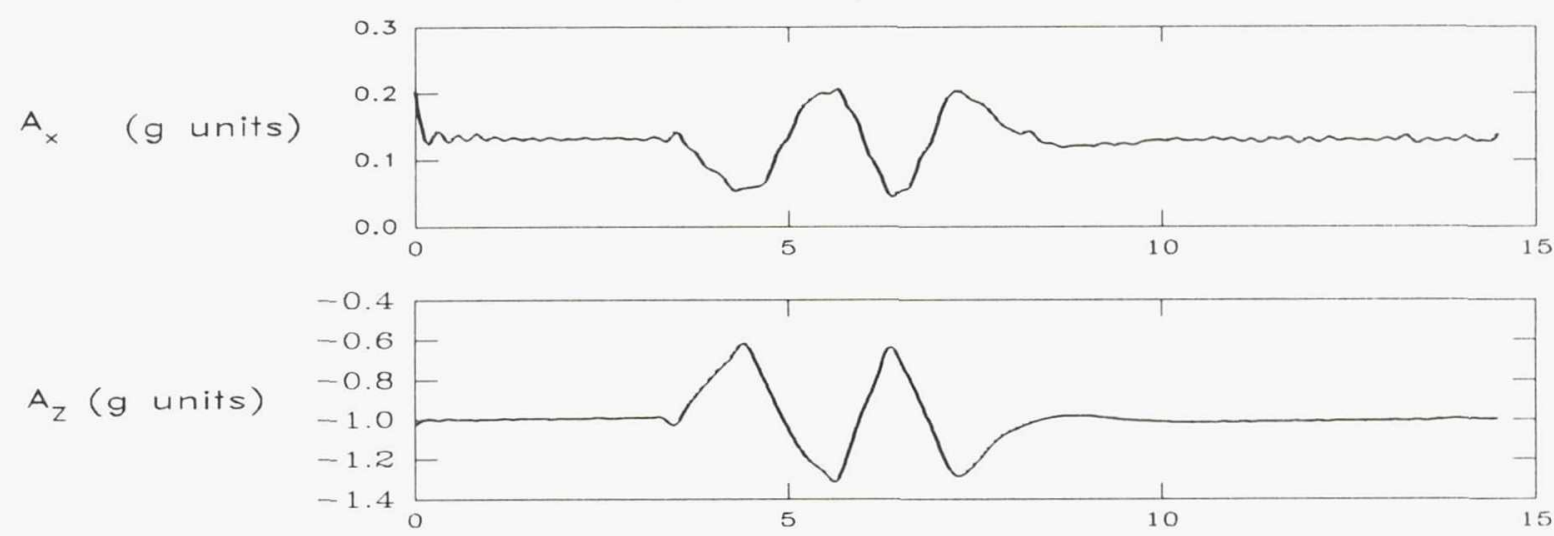

$q(\operatorname{deg} / s)$
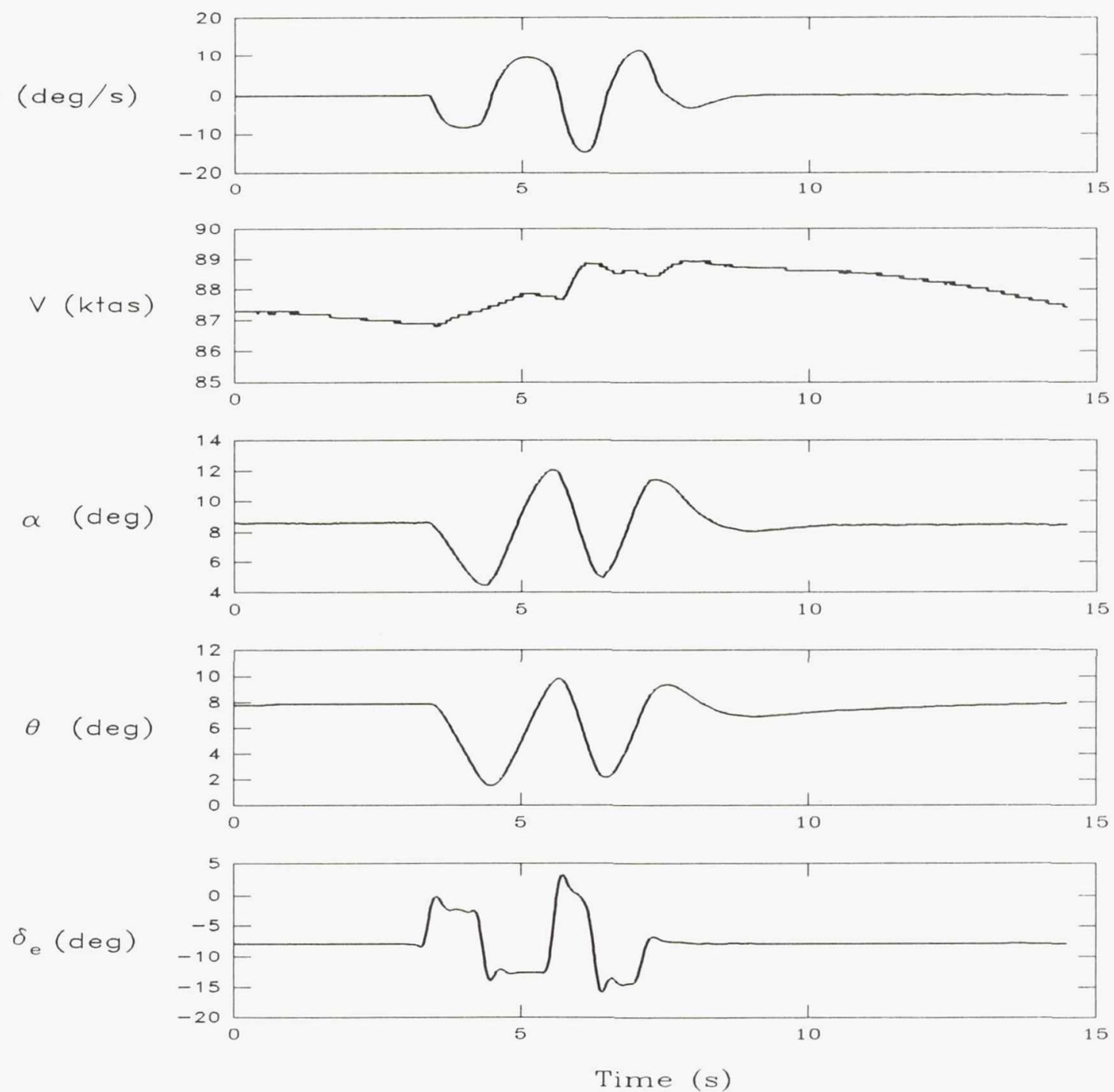

Figure 3: Longitudinal Parameter Identification Maneuver 
$A_{Y}$ (g units)

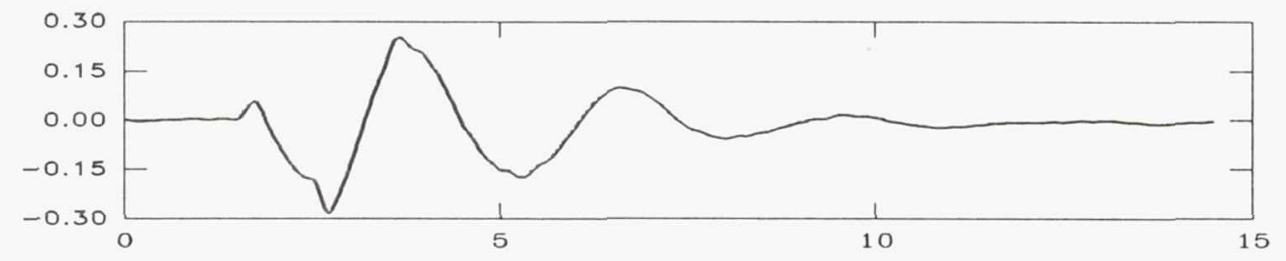

$p(d e g / s)$

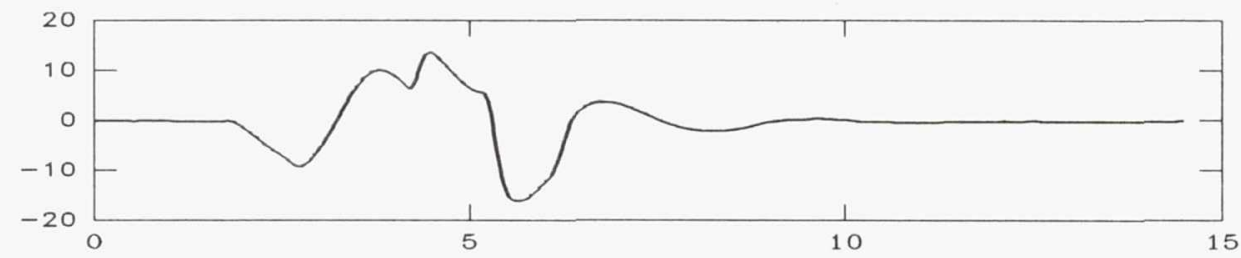

$r(d e g / s)$

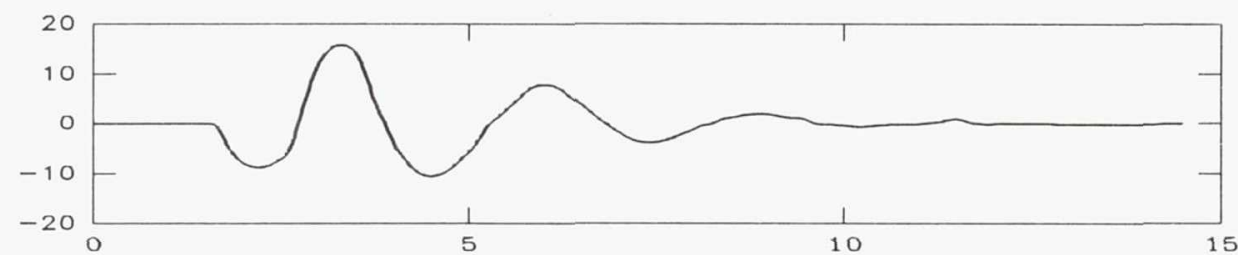

$\beta \quad($ deg $)$
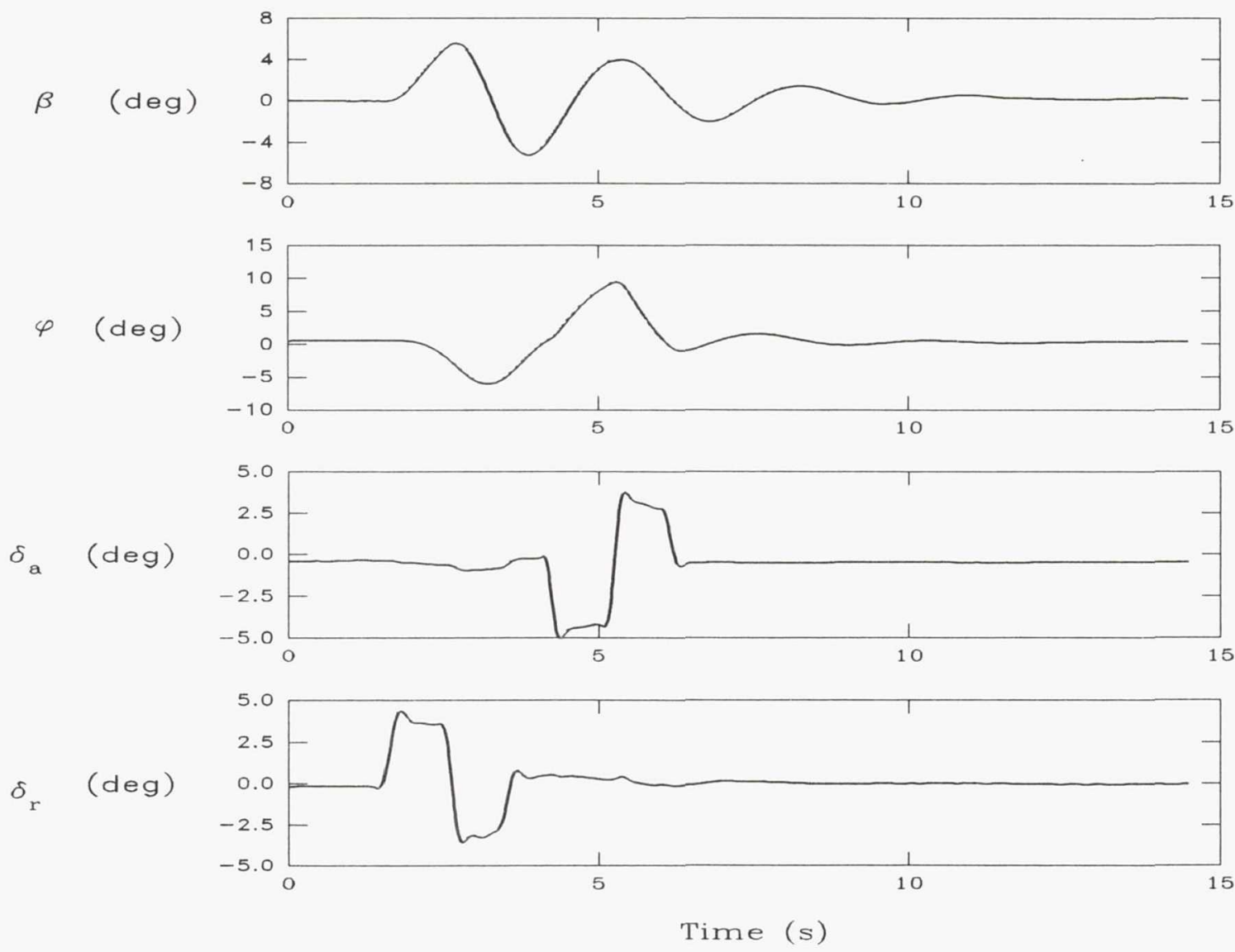

Figure 4: Lateral Parameter Identification Maneuver 


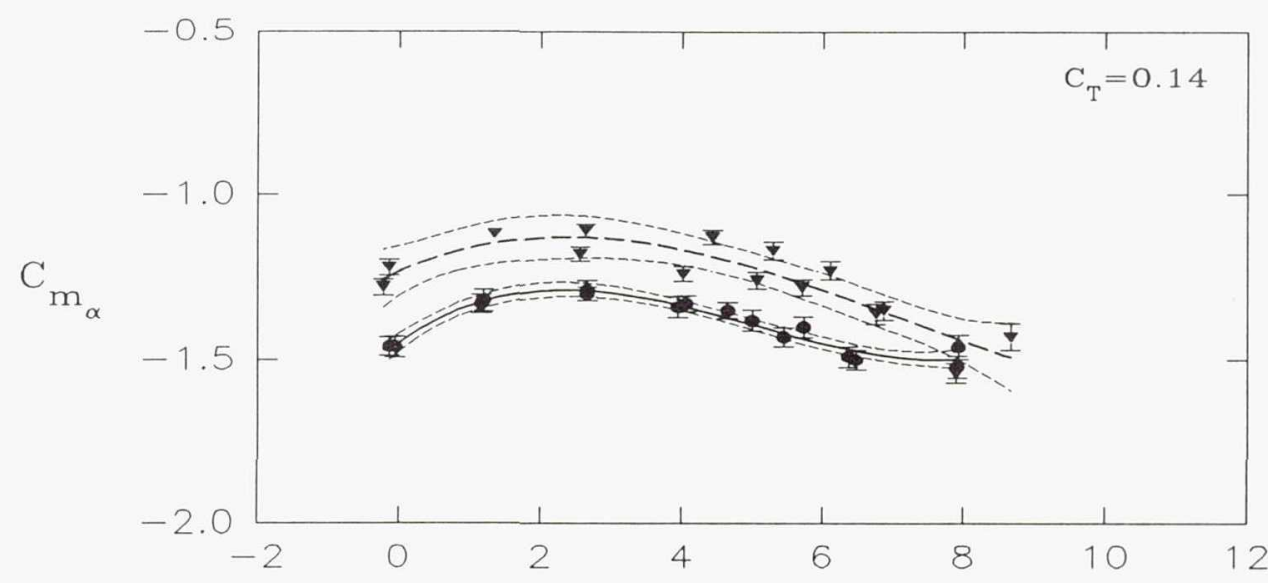

- UNICED

- ICED
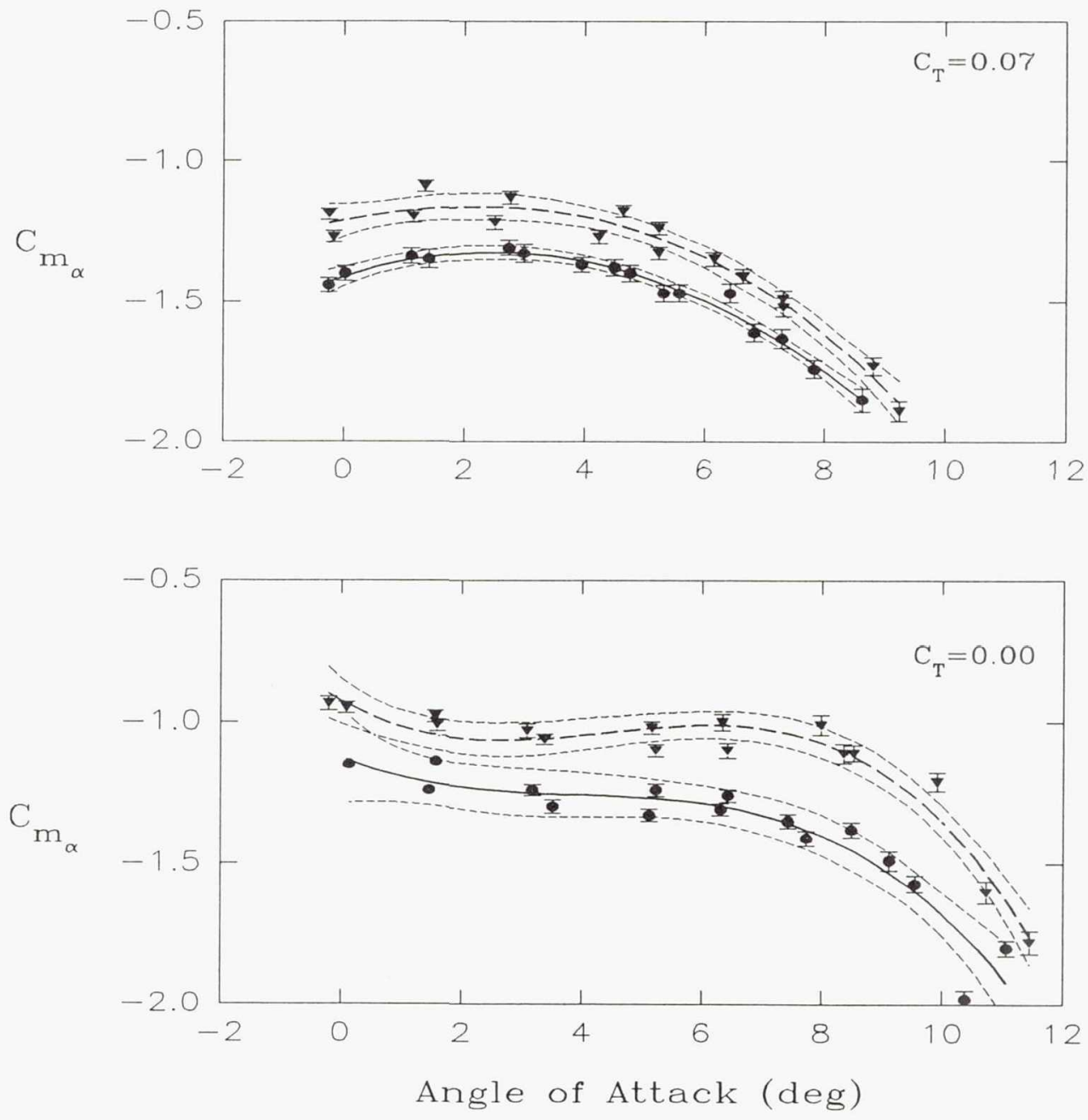

Figure 5: Static longitudinal stability derivative with $95 \%$ confidence limits. $\delta_{F}=0^{\circ}$ 


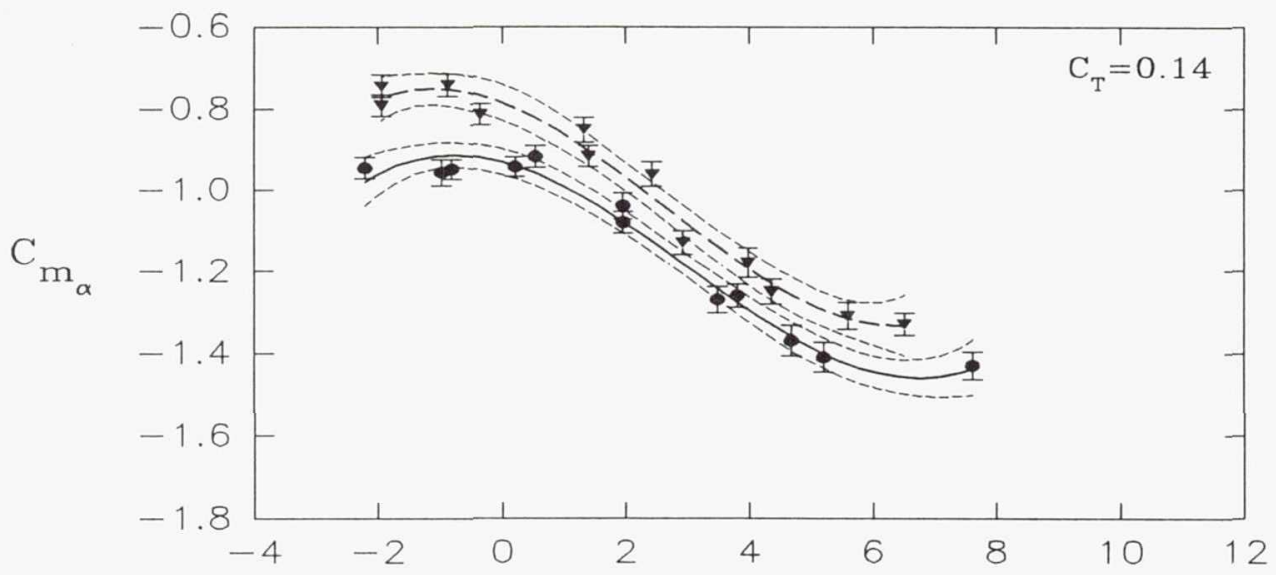

- UNICED

$\checkmark$ ICED
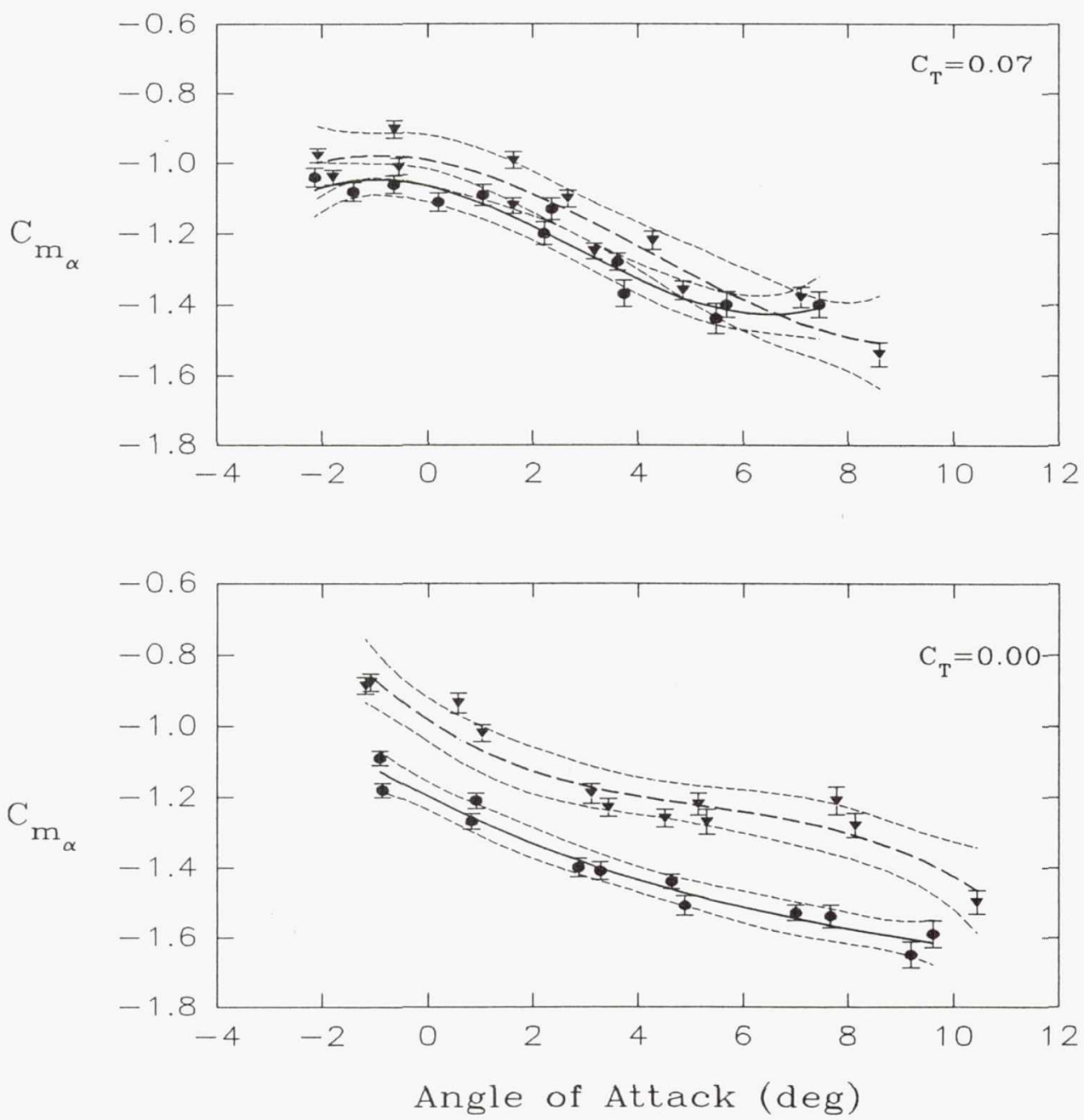

Figure 6: Static longitudinal stability derivative with $95 \%$ confidence bounds. $\delta_{F}=10^{\circ}$ 

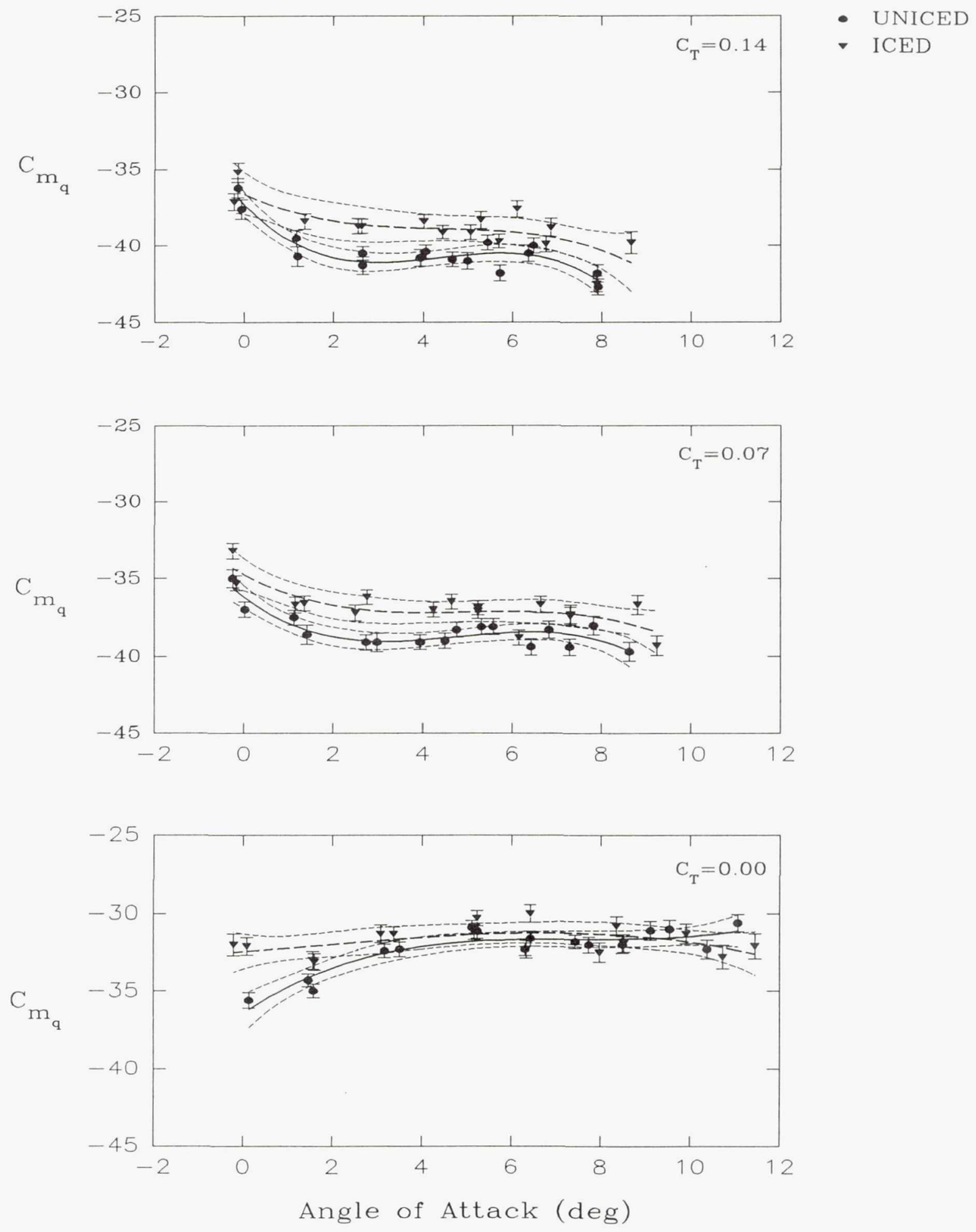

Figure 7: Pitch damping derivative with $95 \%$ confidence bounds. $\delta_{F}=0^{\circ}$ 

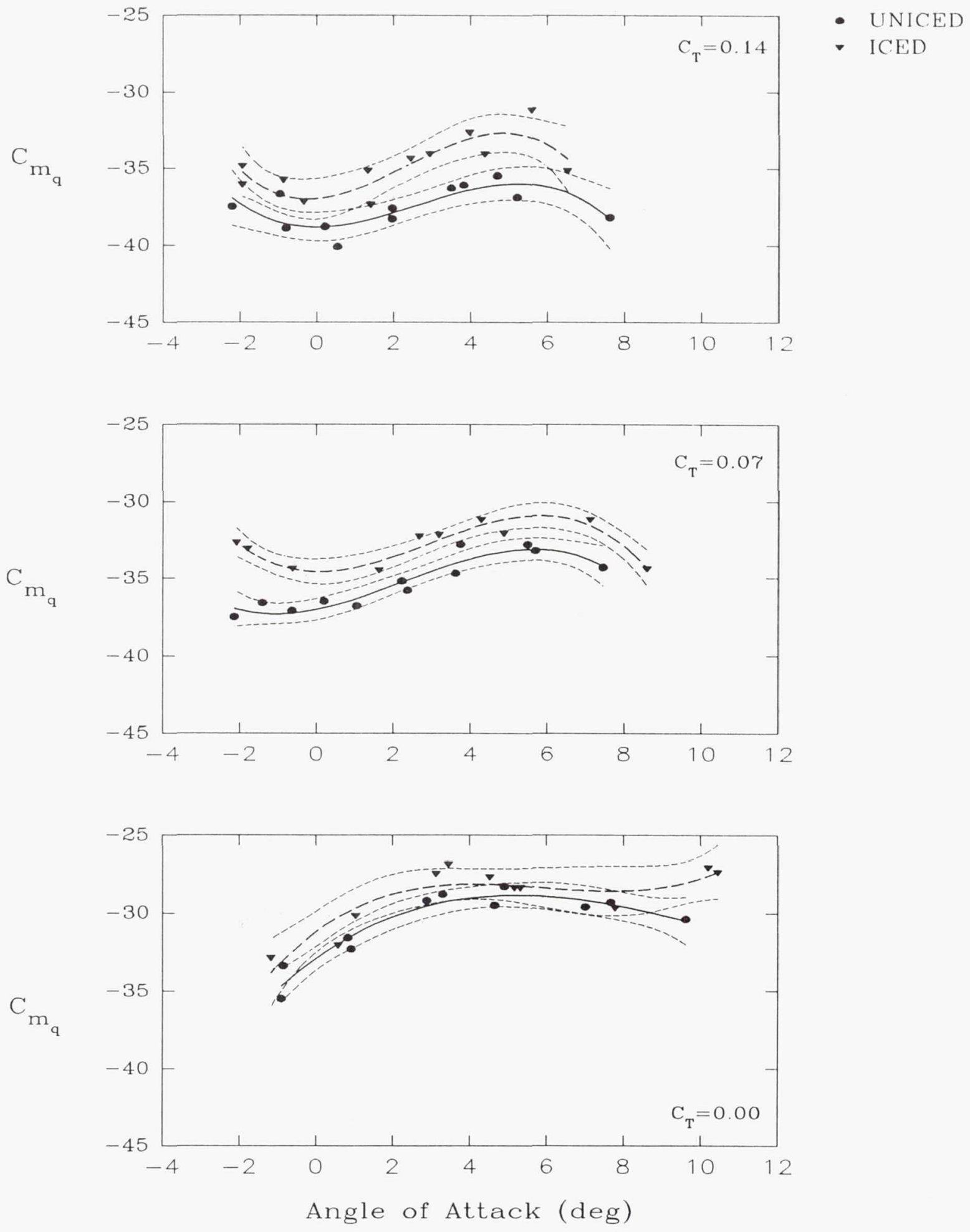

Figure 8: Pitch damping derivative with $95 \%$ confidence bounds. $\delta_{F}=10^{\circ}$ 


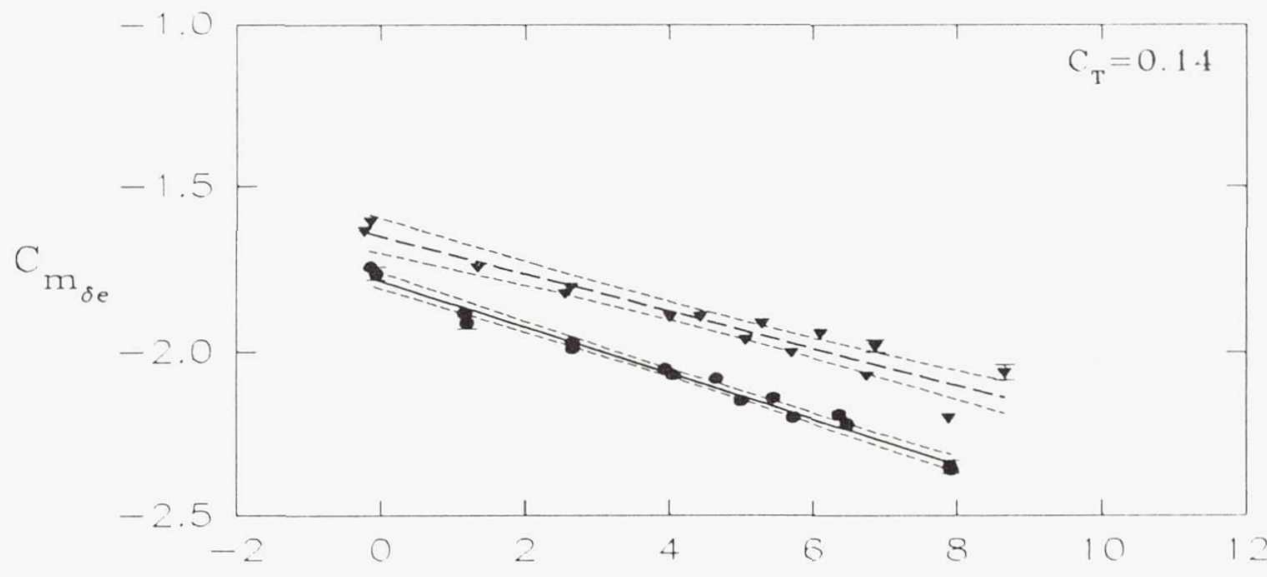

- INICED

- ICED
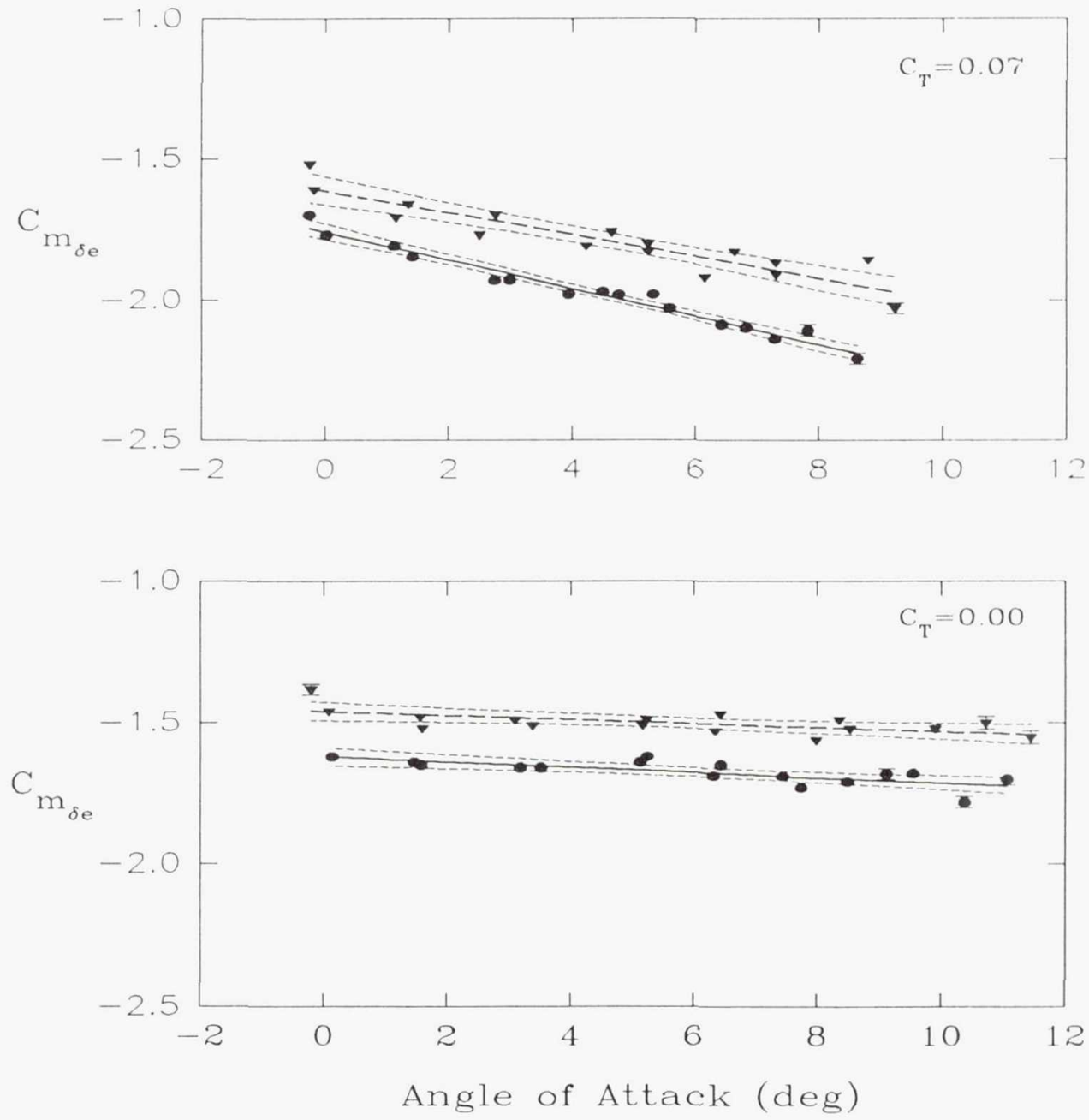

Figure 9: Elevator effectiveness derivative with $95 \%$ confidence bounds. $\delta_{F}=0^{\circ}$ 


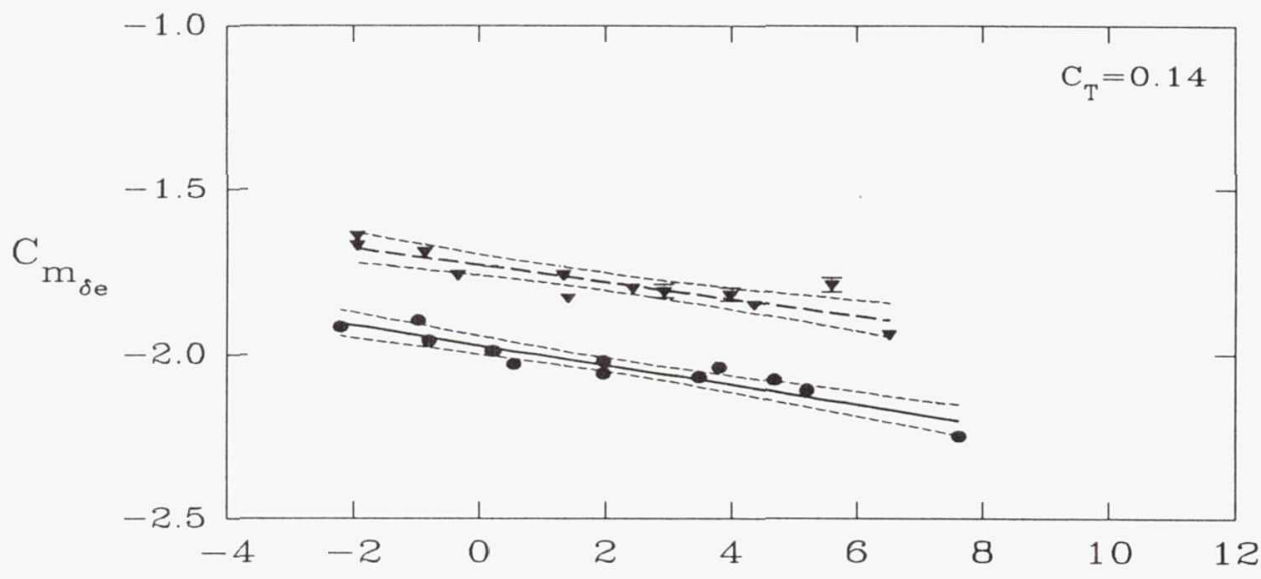

- UNICED

- ICED
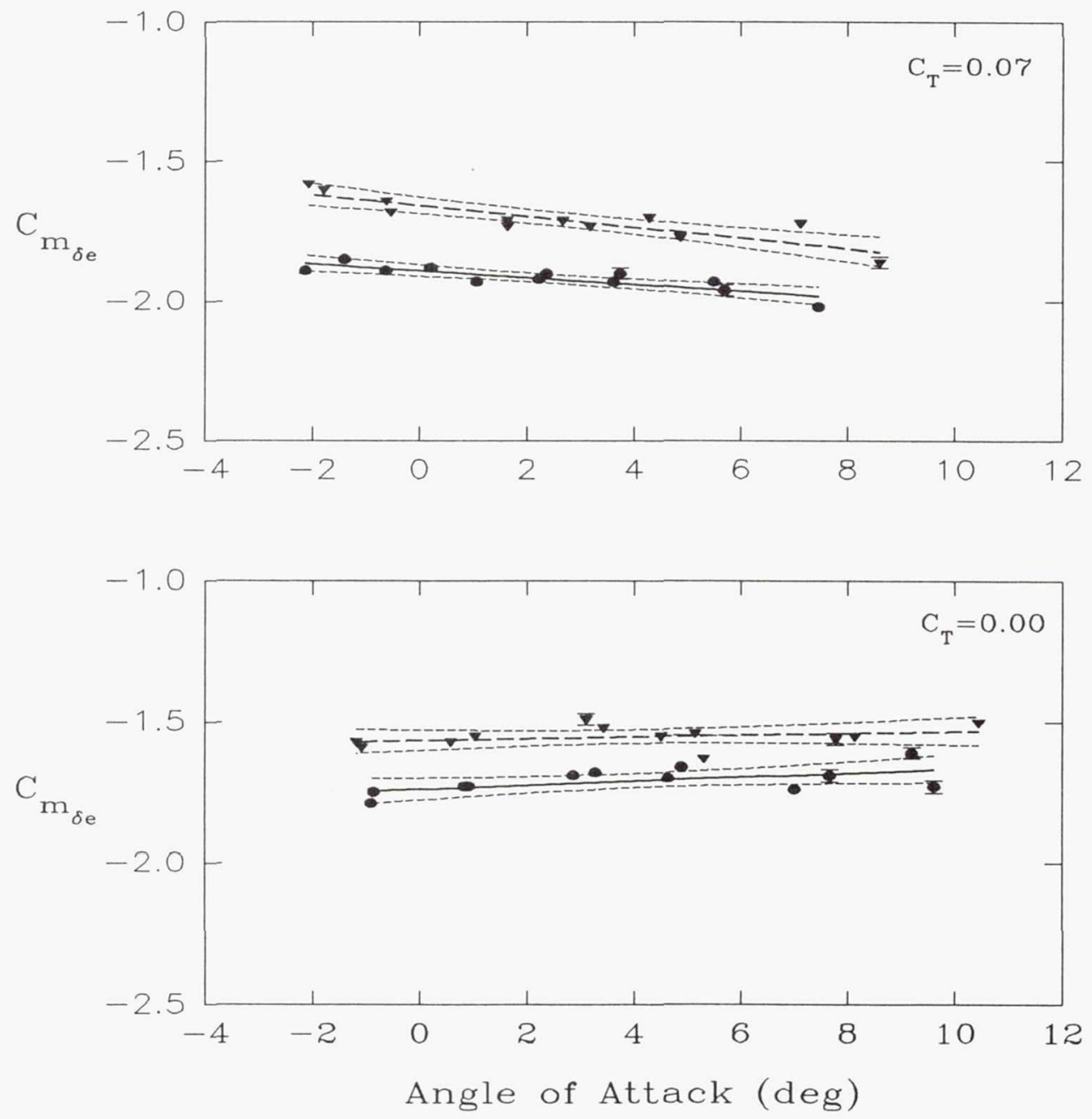

Figure 10: Elevator effectiveness derivative with $95 \%$ confidence bounds. $\delta_{\mathrm{F}}=10^{\circ}$ 


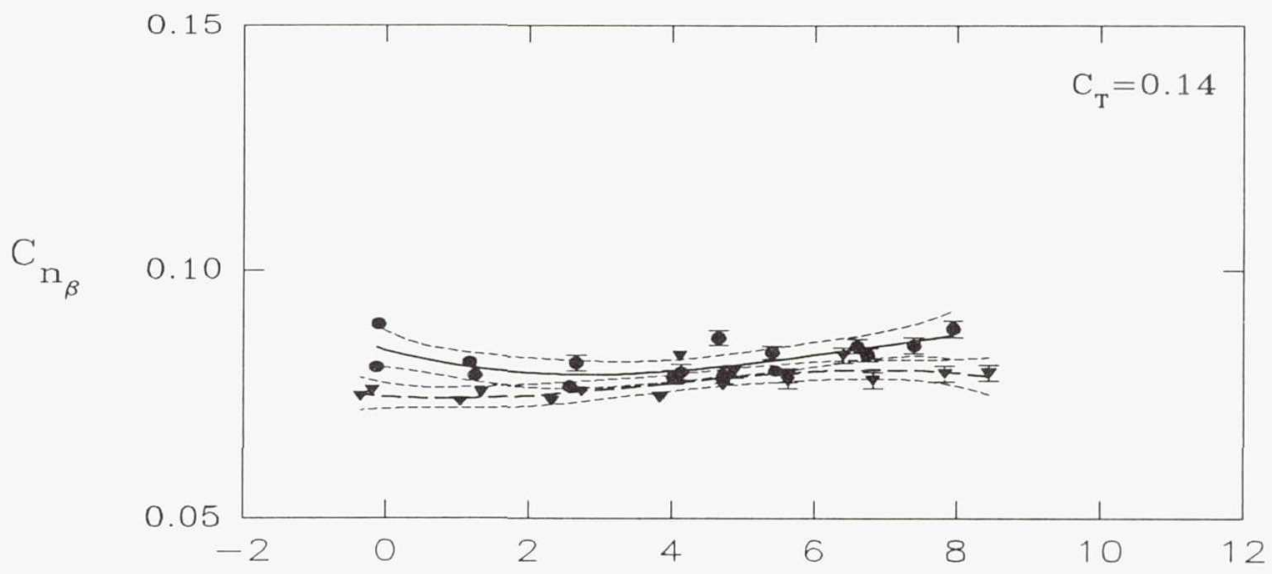

- UNICED

$\checkmark$ ICED
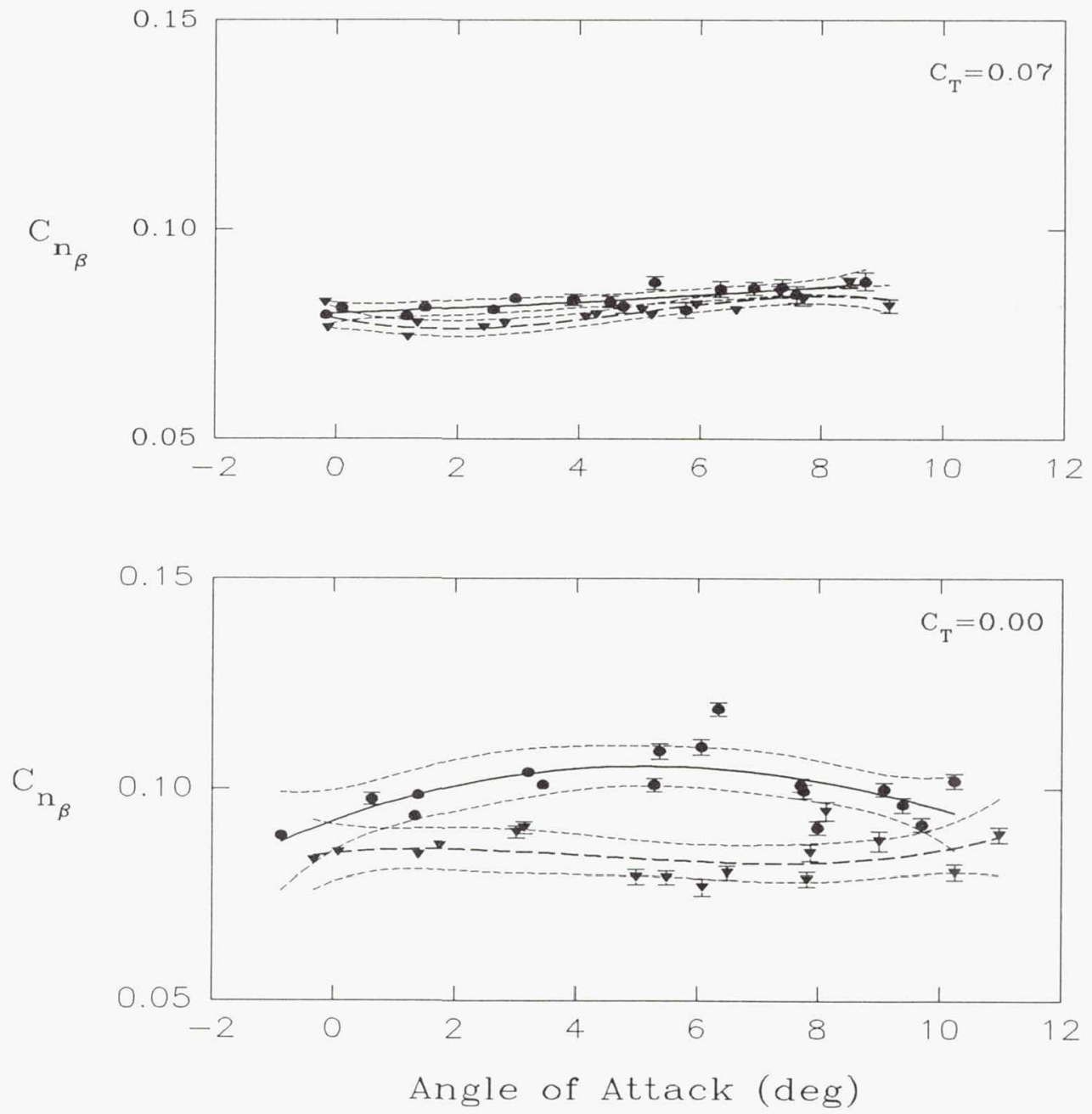

Figure 11: Directional stability derivative with $95 \%$ confidence bounds. $\delta_{F}=0^{\circ}$ 


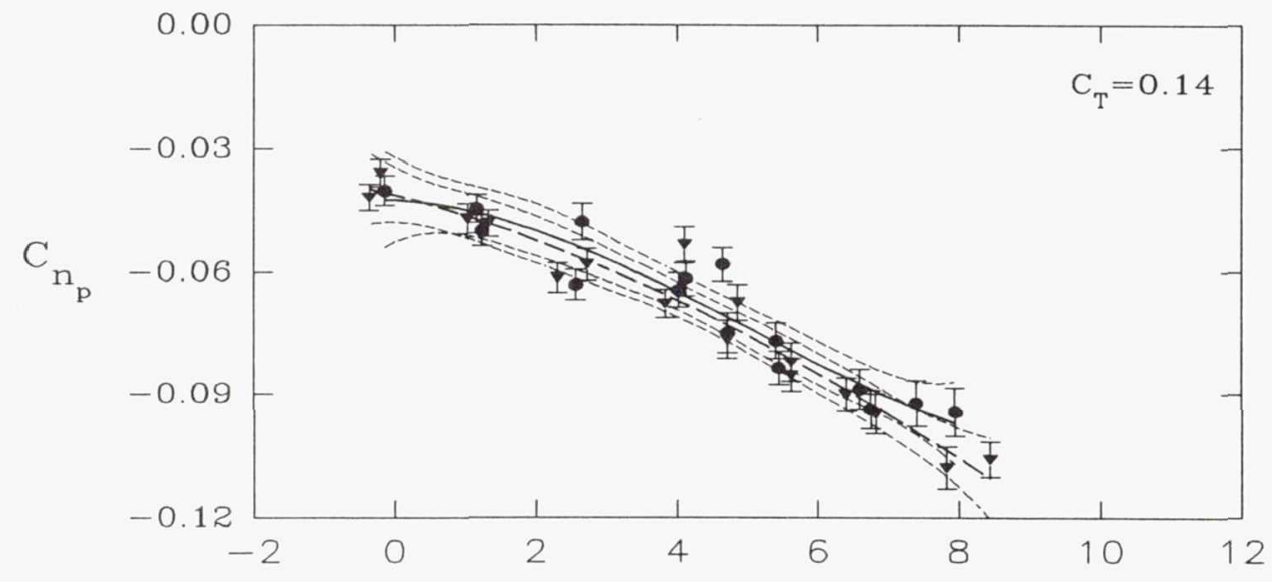

- UNICED

- ICED
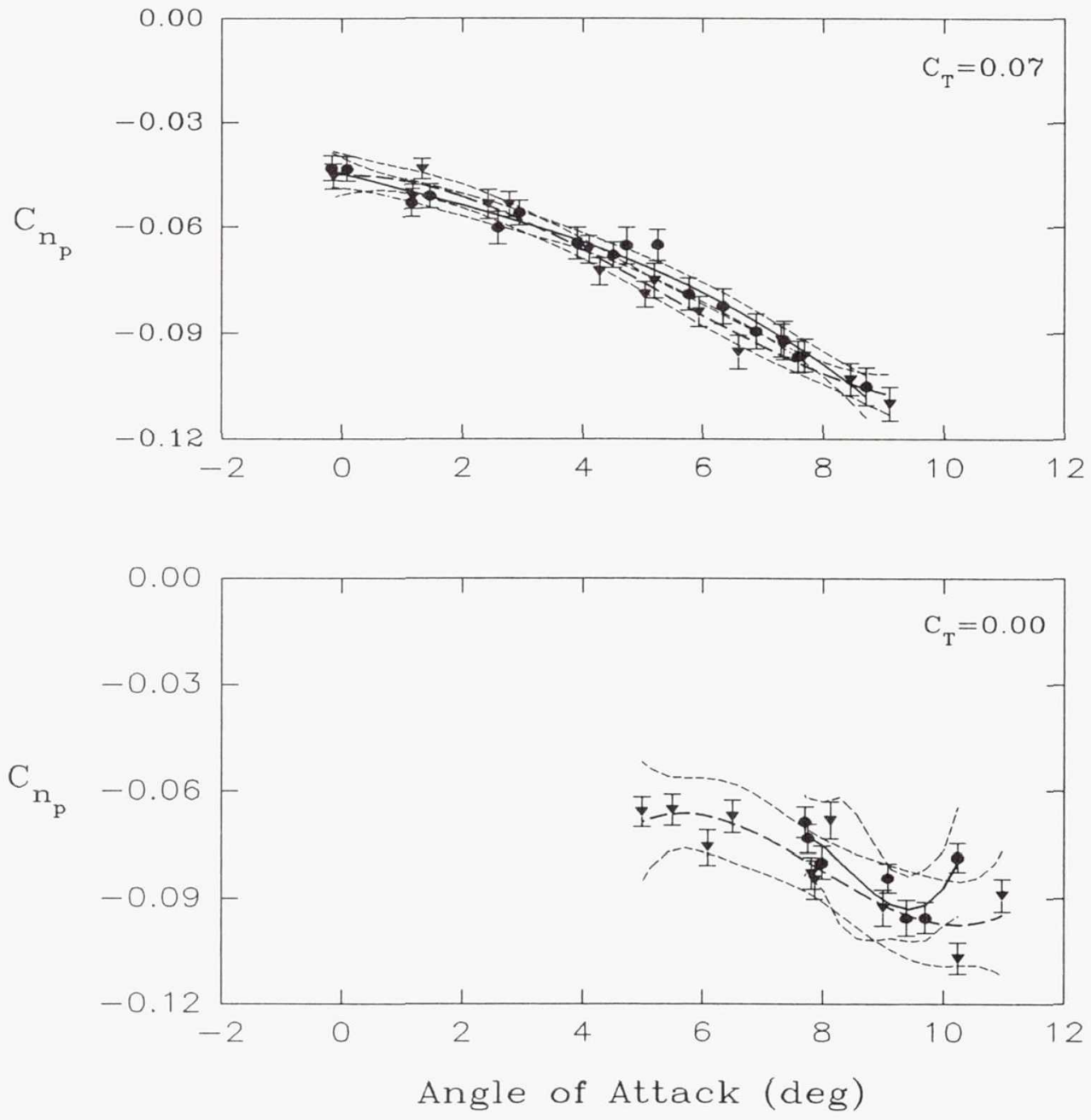

Figure 12: Directional cross-derivative with $95 \%$ confidence bounds. $\delta_{F}=0^{\circ}$ 


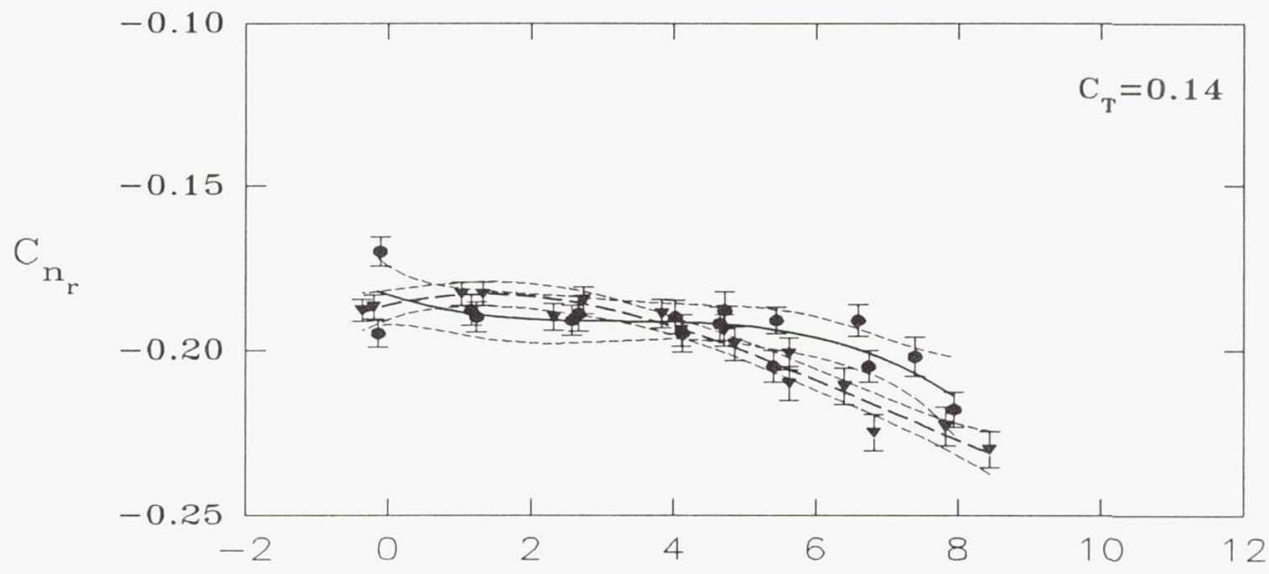

- UNICED

- ICED
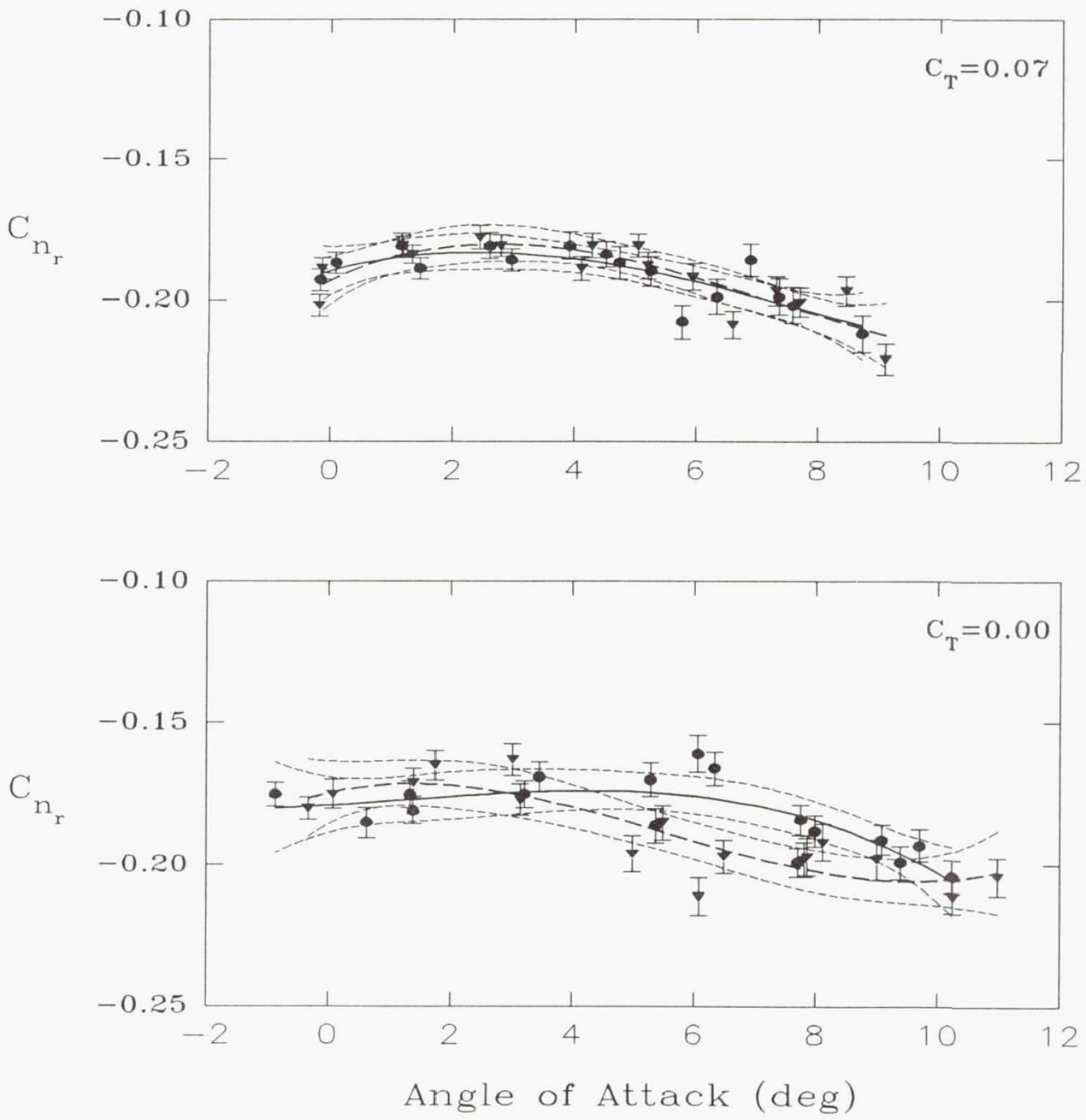

Figure 13: Directional damping derivative with $95 \%$ confidence bounds. $\delta_{\mathrm{F}}=0^{\circ}$ 


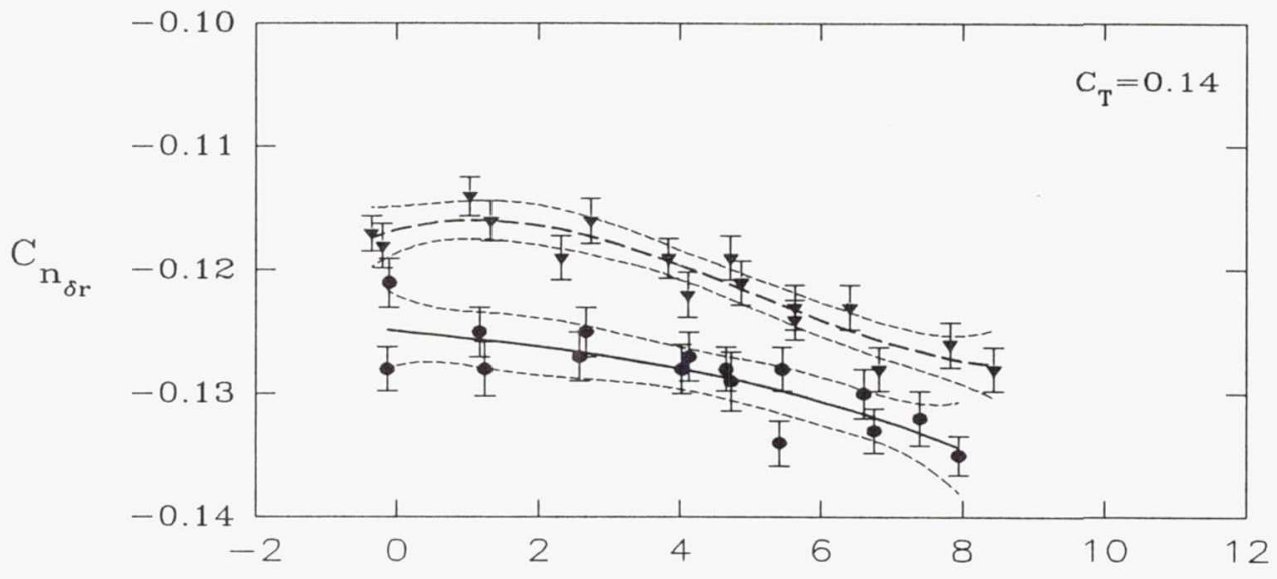

- UNICED

- ICED
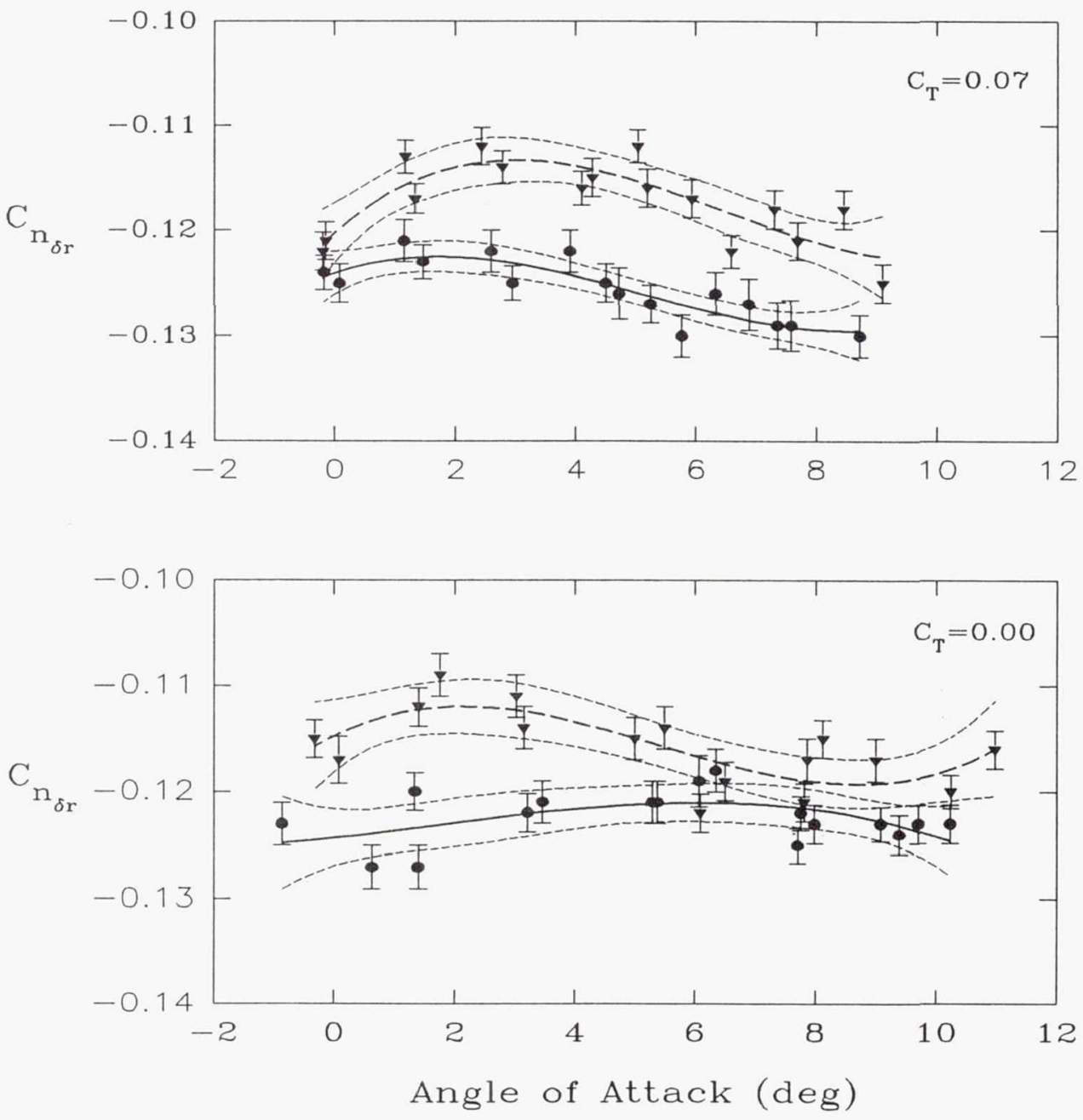

Figure 14: Rudder effectiveness derivative with $95 \%$ confidence bounds. $\delta_{F}=0^{\circ}$ 


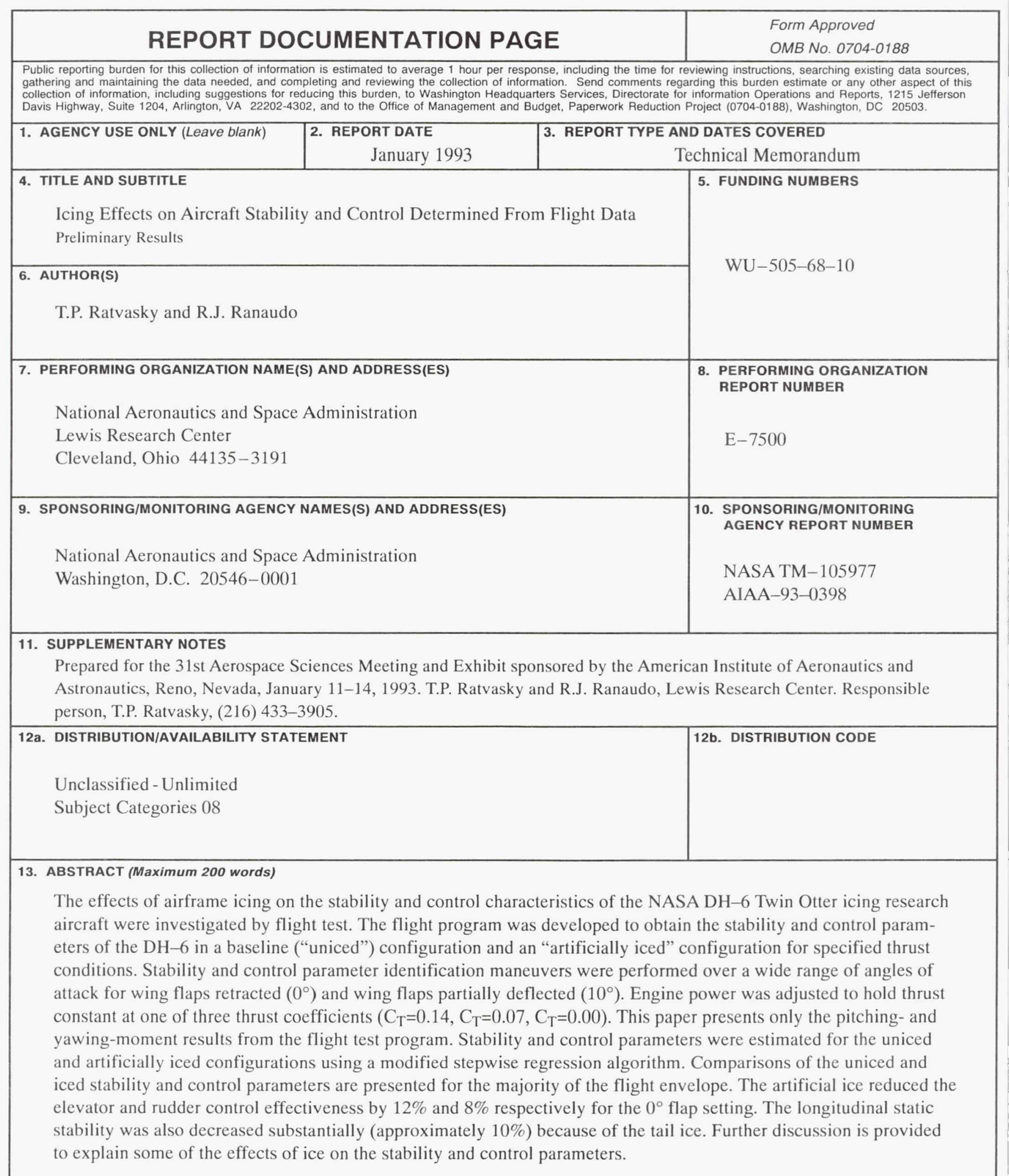


National Aeronautics and Space Administration

Lewis Research Center

Cleveland, Ohio 44135

Official Business

Penalty for Private Use $\$ 300$
FOURTH CLASS MAIL

|||||

ADDRESS CORRECTION REQUESTED

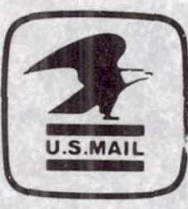

Postage and Fees Paid

National Aeronautics an

Space Administration

NASA 451 